OPEN ACCESS

Edited by:

Furio Colivicchi,

Ospedale San Filippo Neri, Italy

Reviewed by:

Chung-Lieh Hung,

Hsinchu Mackay Memorial

Hospital, Taiwan

Alvaro Aceña,

University Hospital Fundación Jiménez

Díaz, Spain

${ }^{*}$ Correspondence:

Luca Esposito

lucesposito@unisa.it

Specialty section

This article was submitted to

Coronary Artery Disease,

a section of the journal

Frontiers in Cardiovascular Medicine

Received: 05 November 2021

Accepted: 27 December 2021

Published: 04 February 2022

Citation:

Esposito L, Di Maio M, Silverio A,

Cancro FP, Bellino M, Attisano T,

Tarantino FF, Esposito G,

Vecchione $C$, Galasso $\mathrm{G}$ and Baldi $\mathrm{C}$

(2022) Treatment and Outcome of

Patients With Coronary Artery Ectasia:

Current Evidence and Novel

Opportunities for an Old Dilemma.

Front. Cardiovasc. Med. 8:805727.

doi: $10.3389 /$ fcvm.2021.805727

\section{Treatment and Outcome of Patients With Coronary Artery Ectasia: Current Evidence and Novel Opportunities for an Old Dilemma}

\author{
Luca Esposito ${ }^{*}$, Marco Di Maio ${ }^{1}$, Angelo Silverio ${ }^{1}$, Francesco Paolo Cancro', \\ Michele Bellino ${ }^{1}$, Tiziana Attisano ${ }^{2}$, Fabio Felice Tarantino ${ }^{3}$, Giovanni Esposito ${ }^{4}$, \\ Carmine Vecchione ${ }^{1,5}$, Gennaro Galasso ${ }^{1}$ and Cesare Baldi ${ }^{2}$
}

${ }^{1}$ Department of Medicine, Surgery and Dentistry, University of Salerno, Salerno, Italy, ${ }^{2}$ Division of Interventional Cardiology, Cardiovascular and Thoracic Department, San Giovanni di Dio e Ruggi, Salerno, Italy, ${ }^{3}$ Cath Lab Unit, Cardiovascular Department, Morgagni Hospital, Vecchiazzano-Forli, Italy, ${ }^{4}$ Department of Advanced Biomedical Sciences, Federico II University of Naples, Naples, Italy, ${ }^{5}$ Vascular Pathophysiology Unit, Istituto di Ricovero e Cura a Carattere Scientifico (IRCCS) Neuromed, Pozzilli, Italy

Coronary artery ectasia (CAE) is defined as a diffuse or focal dilation of an epicardial coronary artery, which diameter exceeds by at least 1. 5 times the normal adjacent segment. The term ectasia refers to a diffuse dilation, involving more than $50 \%$ of the length of the vessel, while the term aneurysm defines a focal vessel dilation. CAE is a relatively uncommon angiographic finding and its prevalence ranges between 0.3 and $5 \%$ of patients undergoing coronary angiography. Although its pathophysiology is still unclear, atherosclerosis seems to be the underlying mechanism in most cases. The prognostic role of CAE is also controversial, but previous studies reported a high risk of cardiovascular events and mortality in these patients after percutaneous coronary intervention. Despite the availability of different options for the interventional management of patients with CAE, including covered stent implantation and stent-assisted coil embolization, there is no one standard approach, as therapy is tailored to the individual patient. The abnormal coronary dilation, often associated with high thrombus burden in the setting of acute coronary syndromes, makes the interventional treatment of CAE patients challenging and often complicated by distal thrombus embolization and stent malapposition. Moreover, the optimal antithrombotic therapy is debated and includes dual antiplatelet therapy, anticoagulation, or a combination of them. In this review we aimed to provide an overview of the pathophysiology, classification, clinical presentation, natural history, and management of patients with CAE, with a focus on the challenges for both clinical and interventional cardiologists in daily clinical practice.

Keywords: coronary artery ectasia, percutaneous coronary intervention, coronary artery disease, acute coronary syndrome, antithrombotic therapy 


\section{INTRODUCTION}

Coronary artery ectasia (CAE) is defined as a diffuse or focal dilation of an epicardial coronary artery, with a diameter that exceeds of at least 1.5 times the normal adjacent segment. It is described in up to $5 \%$ of all comers' patients undergoing coronary angiography, but with a considerable variability in relation to the patients' clinical presentation and the definition adopted for CAE $(1,2)$. While atherosclerosis seems to be the most frequent etiopathogenetic mechanism, other possible causes include systemic inflammatory vasculitis, connective tissue disorders, genetic diseases, infections, and iatrogenic injury following percutaneous coronary intervention (PCI) $(3,4)$. CAE shows a wide spectrum of clinical manifestations, ranging from incidental findings in asymptomatic patients, to effort angina, exerciseinduced ischemia, and acute coronary syndrome (ACS) $(5,6)$. Although the prognosis of CAE still represents a matter of debate, several studies reported a high risk of adverse events at longterm follow up in patients with myocardial infarction (MI) and angiographic evidence of CAE (7-9). The treatment of patients with CAE constitutes an unsolved problem both for clinical and interventional cardiologists since each therapeutic option offers its own advantages and drawbacks in this setting. The abnormal coronary dilatation and flow disturbances, often associated with high thrombus burden in patients with MI, advocate more potent and prolonged antithrombotic therapies. However, in absence of robust large-scale data, the pharmacological treatment is not standardized yet and still relies on the choice of the clinicians based on their own experience.

The aim of the present review is to outline the classification, etiopathogenesis, clinical presentation and diagnostic assessment of CAE, with a specific focus on management strategies and long-term outcome.

\section{DEFINITION AND CLASSIFICATION}

To date the definition of CAE remains uncertain: the lexical variability prevents to accumulate the data for robust scientific evidence on this issue. The mainstream of the literature directs the nomenclature on the basic distinction between the terms ectasia and aneurysm that, although sometimes used as synonyms, represent two different phenotypes of the disease: while the first one identifies a diffuse dilatation that involves $>$ of $50 \%$ of the length of the vessel, the term coronary artery aneurysm (CAA) refers a focal dilatation (10). CAAs are also subclassified into saccular if the transverse diameter exceeds the longitudinal diameter, and fusiform in the opposite case. Giant CAAs are defined instead as a dilatation with a diameter $>20 \mathrm{~mm}$ or if the diameter exceeds the reference vessel diameter by $>4$ times in adults, while in children if the diameter is $>8 \mathrm{~mm}(11,12)$. Moreover, according to the integrity of the vessel architecture, CAAs can be also divided into true or pseudoaneurysms. While true CAAs involve the three layers of vessel tunica, pseudoaneurysms are single- or double-layer dilatations that occurs after the disruption of the media and external elastic membrane, usually caused by blunt chest trauma or mechanical damage during PCI (13-15). A topographical classification of CAE was proposed by Markis et al. Briefly, CAE is divided into 4 anatomical phenotypes according to its extension in the coronary tree: diffuse ectasia of two or three vessels is classified as type I, diffuse ectasia in one vessel and focal dilatation in another vessel as type II, diffuse ectasia of one vessel only and focal aneurysm as type III and IV, respectively (16). Angiographical subtypes according to Markis classification are shown in Figure 1.

\section{EPIDEMIOLOGY}

CAE is a relatively uncommon angiographic finding, with a prevalence ranging from 0.3 to $5 \%$ of all comers' patients undergoing coronary angiography $(1,2,17)$. The wide variability in the reported prevalence has several reasons, including the lack of homogeneity in the adopted definition of CAE, a certain interoperator variability in the angiographic evaluation, geographical discrepancies, and the different clinical presentations of the patients included in the studies. Indeed, an even higher prevalence of CAE was reported in specific clinical settings, reaching up to $9 \%$ in some cohorts of patients with STsegment elevation MI (STEMI) (7). Nevertheless, since studies include only patients undergoing coronary angiography and/or presenting with ACS, it is reasonable to think that the real prevalence in the general population may be overestimated.

Several reports showed a gender predominance with a high prevalence of CAE in men $(1,18,19)$. Hypertension, smoking and dyslipidemia, including familial hypercholesterolemia, have also been associated with CAE (20-22). A higher risk of CAE was also reported among cocaine abusers (23). Nevertheless, in contrast with coronary artery disease (CAD), CAE has an inverse association with diabetes mellitus $(24,25)$. Since diabetes mellitus promote negative remodeling of the artery wall, the impairment of compensatory vessel enlargement might explain the lower prevalence of CAE in diabetic patients (26).

Right coronary artery (RCA) is the most frequently involved, followed by left anterior descending (LAD), left circumflex (LCx), and less frequently left main (LM) (26).

CAE has been frequently reported in patients with aneurysms in other vascular beds, such as ascending and abdominal aorta and pulmonary arteries (27). Moreover, Meindl et al. found that CAE was a common finding in patients with bicuspid aortic valve (BAV), with or without aneurysms of the ascending aorta (28).

\section{ETIOPATHOGENESIS AND PATHOPHYSIOLOGY}

Although the etiopathogenesis of CAE is not fully understood, atherosclerosis seems to be the most frequent cause in adults (18). This hypothesis is supported by the frequent coexistence with $\mathrm{CAD}$ and by the observation of common histopathological findings, like lipid deposition and hyalinization, destruction and reduction of the medial elastic fibers and disruption of the internal and external elastic lamina (16, 29, 30). These observations lead to the assumption of CAE as a variant of CAD (31). 


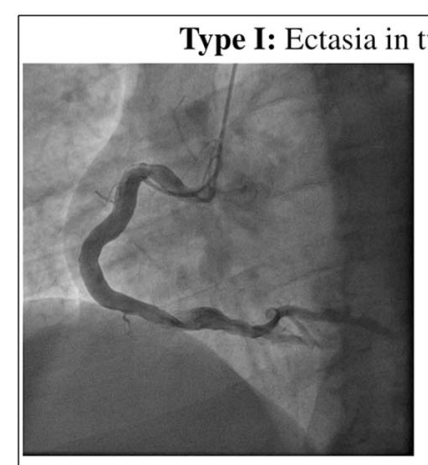

Type III: Ectasia in one vessel

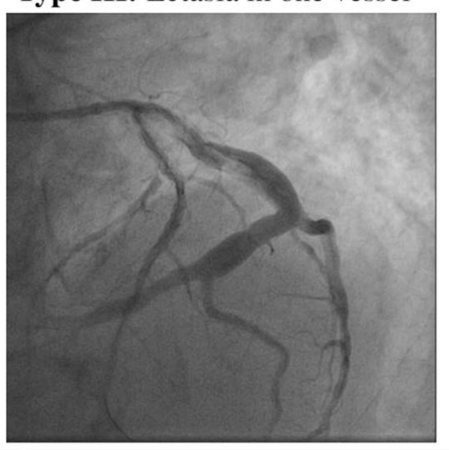

Type II: Ectasia in one vessel and aneurysm of another vessel
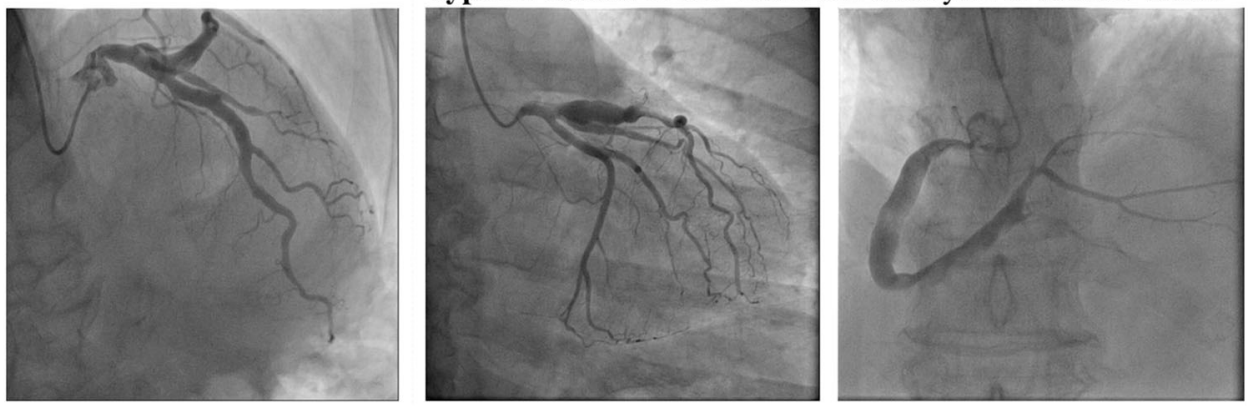

Type IV: Aneurysm of one vessel

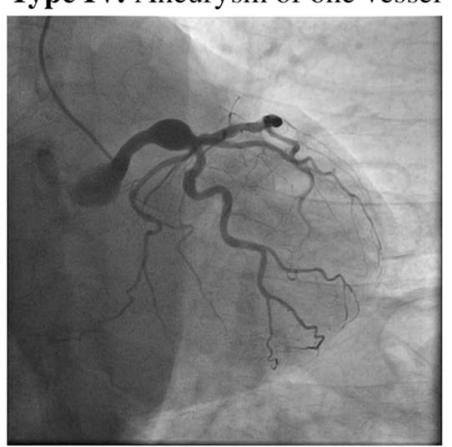

FIGURE 1 | Anatomical definition of CAE according to Markis classification.

However, CAE shows some other histopathological features that are not usually observed in patients with CAD, like the relative preservation of the intima and the extensive loss of musculoelastic components of the media, which is thought to be one of the central mechanisms in the pathogenesis of CAE $(32,33)$. Indeed, an exaggerated activity of metalloproteinases (MMP) has been demonstrated in $\operatorname{CAE}(34,35)$. The extreme proteolysis of extracellular matrix (ECM) weakens the vessel architecture, increase the wall stress, and reduce vessel tolerance to blood flow, thus predisposing to the progressive dilatation of the artery. Moreover, chronic inflammation further contributes to arterial wall damage and dilatation, as demonstrated by the correlation between high levels of inflammatory markers and the presence and the severity of CAE (36-38). However, while inflammation represents one of the major features of the pathophysiology and natural history of atherosclerosis, recent findings demonstrated an increased inflammatory status in patients with CAE compared to those with CAD alone, with significantly higher levels of circulating cytokines (39). Therefore, it might be reductive to categorize CAE as a simple variant of CAD. CAE could rather be considered as the coronary manifestation of an aggressive phenotype of systemic vascular disease, pathogenetically linked to CAD in most cases, despite some morphological, pathophysiological, and clinical discrepancies with the typical atherosclerotic disease.

The coexistence with other conditions, such as BAV and aortic aneurysms, corroborates the conception of CAE as the manifestation of a systemic disease, in which individual genetical susceptibility might be one of the contributing factors $(17,28)$.

Systemic inflammatory diseases, infections and connective tissue disorders are other possible causes of CAE $(12,40,41)$. Kawasaki disease $(\mathrm{KD})$, a systemic vasculitis with coronary tropism, is the most common etiology of CAE in childhood (42). $\mathrm{KD}$-associated CAE occurs in up to $23 \%$ of untreated patients and has distinctive anatomical features, such as the preferential involvement of proximal rather than distal segments, and the development of focal rather than diffuse coronary dilatations $(12,43)$. From a pathophysiological perspective, an increased activity of MMPs has been observed also in patients with KD and coronary vasculitis, emerging like a common underlying mechanism that reconciliates $\mathrm{KD}$ with other etiologies of CAE, including CAD-associated forms $(44,45)$.

CAE has also been reported among cocaine users and its pathogenesis may be related to severe hypertension episodes and to the direct endothelial damage caused by drug-induced vasoconstriction (23).

CAAs or pseudoaneurysms are rare but potential complications of PCI, especially following brachytherapy, atherectomy, or drug-eluting stent (DES) implantation (46-48). Residual dissection and deep arterial wall injury caused by oversized balloons or stents, high-pressure balloon inflations and atherectomy, can result in coronary dilatation due to direct vessel injury and secondary healing process (49). Additionally, the release of anti-proliferative drugs after DES 
implantation, while dramatically reducing the risk of instent restenosis (ISR), might potentially cause CAAs due to delayed re-endothelization, impaired healing after vessel injury, inflammatory changes of the medial wall and hypersensitivity reaction to the polymer carrying the drug $(4,50,51)$. However, most of the reported cases refers to the first-generation DES era: the progressive development of new technologies, including the introduction of thinner struts, bioabsorbable or polymer-free DES with improved biocompatibility, and new anti-proliferative drugs, might justify a reduction in the incidence of this complication (52). There are also several reports of CAAs development following bioabsorbable vascular scaffold (BVS) implantation: gradual scaffold degradation, strut discontinuity, and consequential displacement of the BVS might be possible underlying mechanisms (53-55).

A distinct setting of aneurysmatic disease is represented by aortocoronary saphenous vein graft aneurysms (SVGAs). SVGAs are a rare and late complication of coronary artery bypass grafting (CABG), usually occurring after $\sim 15$ years from surgery. As for CAE, etiopathogenesis is not fully understood and several mechanisms have been proposed, including structural deterioration caused by graft atherosclerosis, technical issues related to surgical manipulation and adaptation of vein graft to higher arterial pressure with vessel wall weakening and dilatation. SVGAs usually progress over time, often reaching large diameter, and have a high incidence of life-threatening mechanical complications, such as compression of adjacent structures, fistulous communications, and rupture $(56,57)$.

Figure 2 illustrates the main etiopathogenetic mechanisms of CAE.

\section{CLINICAL PRESENTATION AND DIAGNOSTIC ASSESSMENT}

The clinical manifestations of CAE are heterogeneous, and often it is occasionally recognized during coronary angiography or computed tomography (CT). However, CAE may become clinically overt through different possible scenarios, including ACS, effort angina, exercise-induced ischemia, microvascular dysfunction, compression of adjacent cardiac or non-cardiac structures and the tragical, albeit rare, complication of rupture with acute cardiac tamponade $(5,58-60)$. In patients with CAE, there are several possible mechanisms leading to the clinical event of an ACS: (1) atherosclerotic plaque instability with high thrombus burden; (2) endoluminal thrombosis due to flow disturbances and blood stasis, in absence of underlying atherosclerotic lesions; (3) distal embolization of thrombotic material; (4) impairment of myocardial perfusion related to the severe slow flow, which can be clinically expressed either as ACS or effort angina. Figure 3 illustrates the main mechanisms of ACS in patients with CAE.

The gold standard for the diagnostic assessment of CAE remains coronary angiography: the typical angiographical features are delayed antegrade contrast filling, segmental back flow, and local deposition of dye in the dilated coronary segment, all of them able to depict the severe flow disturbances of CAE.
However, slow flow and blood stasis might complicate the angiographic assessment of CAE, especially when evaluating the true size of the vessel or the presence of thrombotic material. IVUS is useful to better assess vessel wall architecture and to distinguish between true aneurysm, pseudoaneurysm, normal segments with adjacent stenosis or complex plaques angiographically mimicking CAAs (13): this differential diagnosis is crucial for prognostic stratification and therapeutic guidance, due to the high risk of ACS associated with the presence of an ulcerated or ruptured atherosclerotic plaque. Moreover, IVUS might be helpful to precisely estimate the minimal lumen area and the percentage of the stenosis, to evaluate the thrombotic and calcific burden of the lesion, and to guide stent sizing and implantation when PCI is planned (61).

Optical coherence tomography (OCT) is another possible tool in the invasive assessment of CAE. Compared to IVUS, OCT has greater axial and spatial resolution that might be helpful in CAE to assess atherosclerotic plaque features, thrombus burden and mechanisms of PCI failure. However, its application in large vessel is limited by the low penetration depth, with loss of image definition as the distance of the anatomical structures from the lens increases (62).

Other technologies are available for the interventional cardiologist in the toolbox of CAE investigation, but they play a minor role. CT may be helpful in the non-invasive assessment of CAE, increasing the prevalence of incidentally found CAE, which was described as a rare finding on coronary angiography in previous decades $(2,63)$. CT provides important information on CAE anatomical features, such as shape, maximum diameter and presence of concomitant stenosis, avoiding the pitfalls of coronary angiography (64). Furthermore, CT allows a threedimensional reconstruction of the coronary tree that might clarify anatomical and functional relations with other adjacent structures (i.e., fistulous communications with cardiac or noncardiac chambers) $(65,66)$.

Figure 4 shows the role of a multimodality imaging approach in a patient with STEMI and angiographic evidence of CAE.

Magnetic resonance angiography (MRA) is another possible tool in the assessment of CAE, especially in patients with contraindication for other diagnostic techniques. MRA provides important anatomical and functional information, especially in large proximal vessels, while its resolution decreases in smaller and distal segments $(67,68)$.

Transthoracic and transesophageal echocardiography have a role in the evaluation of patients with CAE, especially in children with KD and large CAAs of the proximal LM and RCA. Echocardiography is useful to assess the location of the CAA and the presence of intraluminal thrombi. Given its non-invasive nature, it is an ideal method for long-term follow up in adulthood of patients with history of $\mathrm{KD}$ (43).

\section{NATURAL HISTORY AND PROGNOSTIC STRATIFICATION}

The long-term outcome of patients with CAE has been poorly investigated. Although flow disturbances, enhanced 


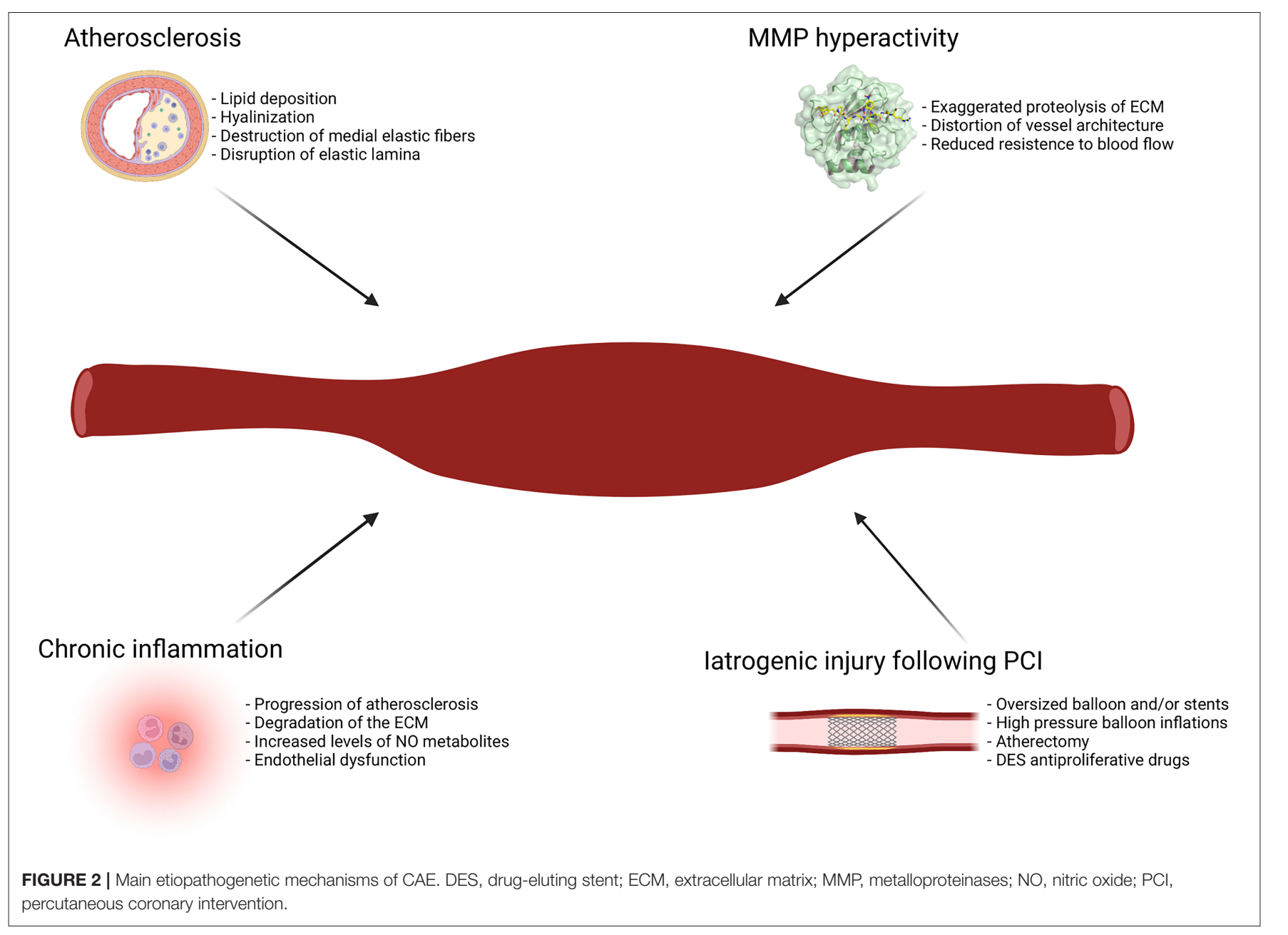

thrombogenicity and high risk of procedural drawbacks during PCI would be perceived as associated to unfavorable prognosis, literature does not provide conclusive evidence on the clinical outcome of patients with CAE. Krüger et al. demonstrated the occurrence of angina and exercise-induced ischemia in patients with isolated $\mathrm{CAE}$ and non-obstructive $\mathrm{CAD}$, suggesting that flow turbulences might potentially impair myocardial perfusion even in absence of coexisting significant stenoses (5). However, the prognostic role of isolated CAE still needs to be clarified. Furthermore, it is not clear whether CAE confers additional risk in patients with coexisting CAD. In a large series from the CASS study, the presence of CAE did not affect the adjusted 5year survival of patients with CAD (1). Similar findings were reported by Demopoulos et al. with no evidence of additional risk of adverse events in patients with CAE (18). In opposition, Baman et al. found that CAE had an independent adverse effect on long term mortality, without significant differences between patients with and without CAD (69). Several reasons might explain the inconsistency between these studies, such as the small number of patients included, the lack of an adequate follow-up and the heterogeneity in the adopted definition of CAE.
Nonetheless, recent evidence demonstrated a high risk of cardiovascular events at long term in patients with ACS and angiographic evidence of CAE. The prognostic implications of CAE in the high-risk clinical setting of ACS might have several explanations. First, the presence of an ectatic infarct-related artery (EIRA), often associated with high complexity of the lesion and large thrombus burden, might affect per se the procedural success of PCI and the long-term clinical outcome of these patients. Bogana Shanmugam et al. compared 25 STEMI patients with an EIRA to a cohort of 80 non-EIRA STEMI patients and found that the EIRA group, despite similar in-hospital outcomes, had a higher incidence of long-term cardiovascular events, particularly driven by recurrent MI, unstable angina (UA), and need for surgical revascularization (70). Conversely, in a recent metanalysis of 6 observational studies on patients with STEMI treated with primary PCI, no difference in terms of mortality were reported between CAE and non-CAE patients, despite a higher thrombus burden and a lower post-procedural TIMI flow in the CAE group (71).

Similarly, Ipek et al. showed no difference in terms of inhospital and 1 year mortality and revascularization between STEMI patients with and without EIRA undergoing primary 

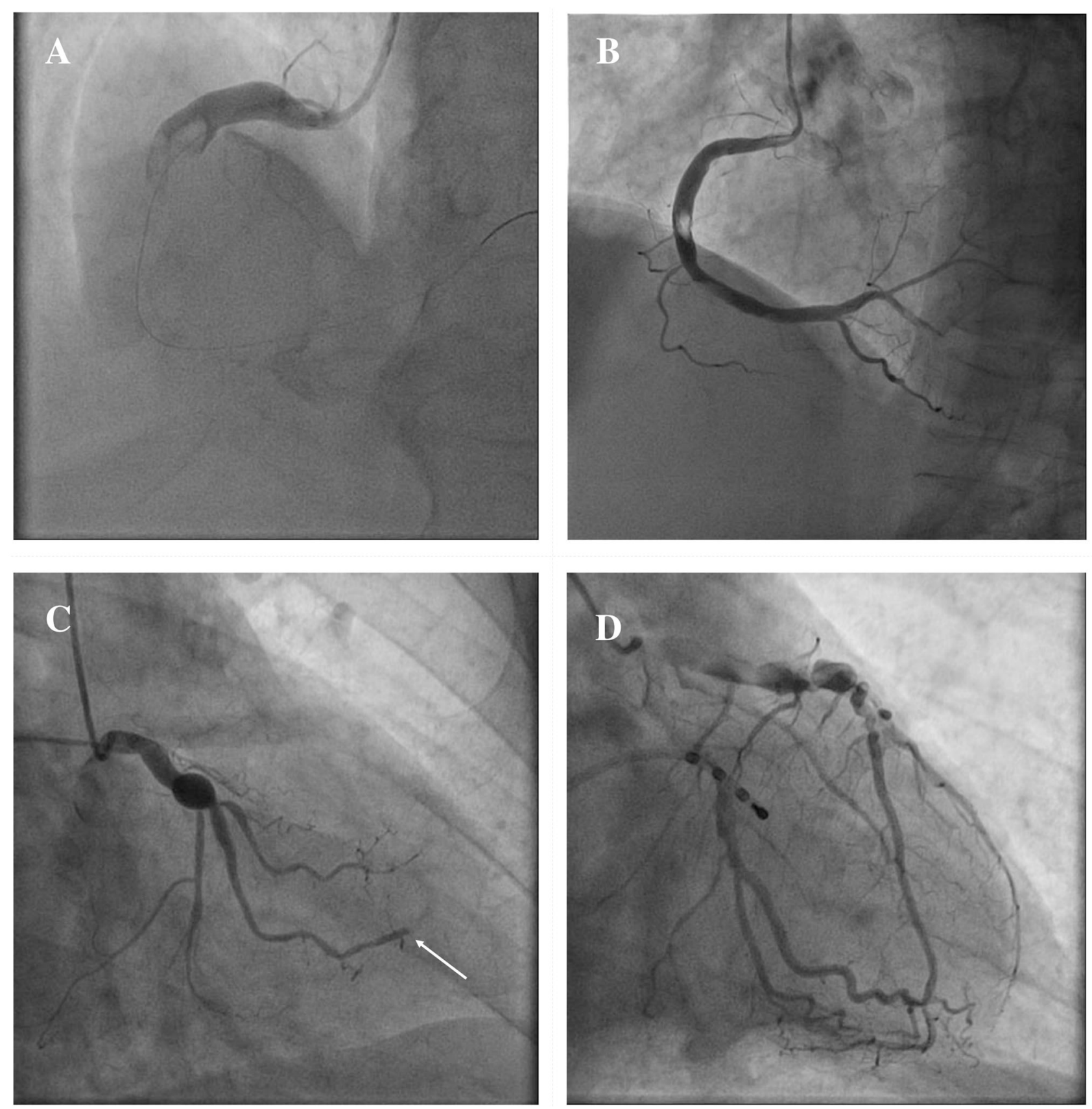

FIGURE 3 | Mechanisms of ACS in patients with CAE. ACS in patients with CAE can occur through different pathophysiological mechanisms. Catastrophic plaque rupture resulting in acute vessel occlusion due to a huge thrombotic burden untreatable despite a timely primary PCI (A). Relevant filling defect due to endoluminal thrombus without significant underlying atherosclerotic plaque, to be ascribed to flow disturbances in an entirely ectatic RCA (B). Abrupt flow occlusion of the distal segment in a marginal branch (arrow) due to the embolization of clot fragments coming from a proximal saccular CAA of the LCx (C). Ectatic LAD showing images of advanced flow disturbances angiographical pattern, that suggest the relationship between impaired blood progression and myocardial ischemia (D). ACS, Acute Coronary Syndrome; CAA, coronary artery aneurysm; CAE, Coronary Artery Ectasia; LAD, left anterior descending; LCx, left circumflex; PCI, percutaneous coronary intervention; RCA, right coronary artery.

PCI, despite a higher rate of no-reflow in the EIRA group (72). However, the unadjusted statistical analysis, the relatively small sample size, the paucity of adverse events, and the shortterm follow-up time might have influenced these findings.
In a study on 643 consecutive patients with STEMI treated with primary $\mathrm{PCI}$, patients with EIRA were compared to a control group of non-EIRA and showed suboptimal procedural result of primary PCI with impaired epicardial flow and 

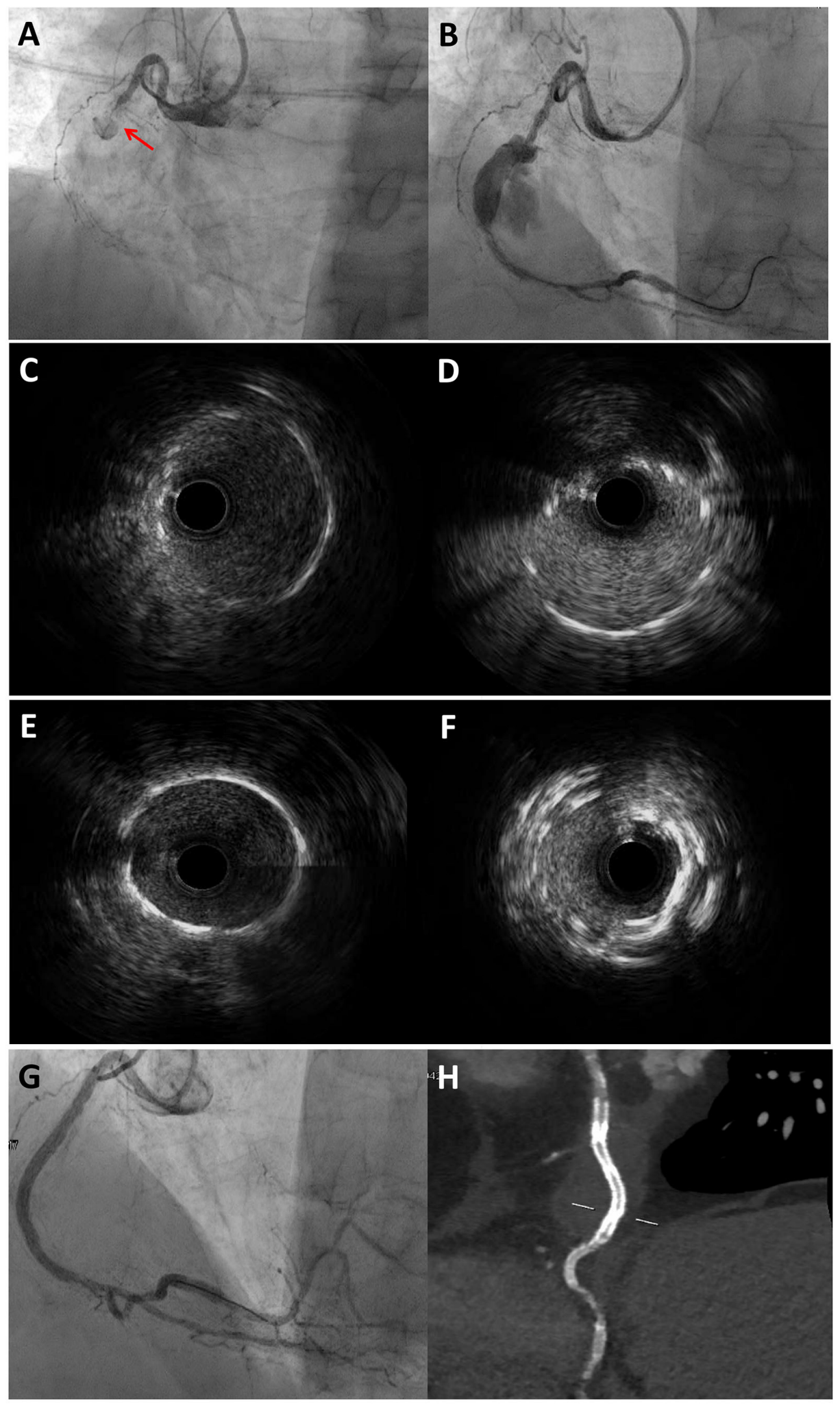

FIGURE 4 | Multimodality imaging approach for diagnosis and PCI guidance in a STEMI patient with angiographic evidence of CAE. 77-year-old man admitted for STEMI, who underwent emergent coronary angiography. Coronary angiography showed an occlusion of the mid RCA due to stent thrombosis (A) and a CAA distal to the occlusion site, which was visible after guidewire crossing and thrombectomy (B). IVUS evaluation showed the previously implanted stents at the proximal (C) 
FIGURE 4 | and distal (D) necks of the CAA. The PCl strategy consisted of $48 \mathrm{~mm}$ EES implantation bridging the proximal and distal CAA necks to create a supporting platform for the deployment of two overlapping covered stents. (E) and (F) show the proximal and distal edges of the EES assessed by IVUS. Coronary angiography showed an optimal sealing of the CAA after the implantation of two overlapping $3.5 \times 24 \mathrm{~mm}$ single-layer PTFE covered stents (BeGraft, Bentley InnoMed, Hechingen, Germany) (G), which was confirmed by CCTA after the procedure (H). ${ }^{*}$ Courtesy of Dr. lacopo Muraca. CAA, coronary artery aneurysm; CCTA, coronary computed tomography angiography; EES, everolimus-eluting stent; IVUS, intravascular ultrasound; PTFE, polytetrafluoroethylene; RCA, right coronary artery; STEMI, ST-segment elevation myocardial infarction.

myocardial perfusion, larger thrombus burden, higher risk of distal embolization and lower ST-segment resolution and vascular collateral development. Moreover, the presence of an EIRA emerged as an independent predictor of adverse outcome (73). However, there are growing evidence that patients with ACS and angiographic evidence of CAE have a high risk of future adverse events at follow up, irrespective of the presence of an EIRA. In a single-center observational study conducted by our group on 534 patients with STEMI, we found that 154 CAE patients developed a higher risk of recurrent MI at longterm follow up compared to a propensity-weighted group of 380 non-CAE STEMI (7). However, no significant differences in allcause death and cardiac death were reported between groups: probably a longer follow up and a larger number of patients might have yielded more conclusive results in terms of long-term mortality. Similarly, an observational study on 1,698 Japanese patients with acute MI showed a significantly higher risk of major cardiac events (defined as the composite of cardiac death and non-fatal MI) in 51 patients with CAE compared to a propensitymatched cohort of 1,647 patients without CAE (8). Furthermore, Wang et al. compared the long-term clinical outcome of $174 \mathrm{CAE}$ patients with MI and 4,614 patients with MI and no evidence of CAE: at a median follow up of 4 years, CAE patients showed a significantly higher incidence of the composite of cardiac death, MI, stroke and repeated coronary revascularization; at multivariable analysis, CAE emerged as an independent predictor of recurrent cardiovascular events (74).

In accordance with these findings, Gunasekaran et al. assessed the prognostic significance of CAE anatomical extension in a retrospective study on 317 patients and found that a higher grade of CAE (Markis type I and II) was associated with a significantly higher risk of ACS at long term compared to lower grade of CAE (Markis III and IV), despite similar severity of underlying CAD. Moreover, patients with Thrombolysis In Myocardial Infarction (TIMI) flow $<3$ showed a higher occurrence of ACS at follow up compared to patients with normal epicardial flow, with further adverse impact on outcomes when associated with multivessel CAE (9). A cohort study on 595 Chinese patients with CAE, compared the clinical outcome of the two anatomical phenotypes of CAE, diffuse CAE, or ectasia, and focal CAE, or CAAs: patients with diffuse CAE, compared to the group with focal coronary dilations, showed a significantly higher incidence of major cardiovascular events, defined as cardiovascular death and non-fatal MI, at both propensity-matched and propensityweighted analyses (75). These findings might indicate that a diffuse extension of CAE in the coronary tree results in a greater impairment of coronary flow and a higher risk of thrombotic and embolic events, thus affecting long-term clinical outcome of these patients.
Taking all these findings together, it is reasonable to consider CAE as an aggressive phenotype of coronary disease associated with a multifactorial risk of cardiovascular events at follow up: technical issues of PCI and the intrinsic complexity of the disease lead to the imbalance of coronary hemodynamics, susceptibility to local thrombotic disorders and adverse clinical outcome.

The main studies evaluating clinical outcome of patients with CAE are summarized in Table 1.

\section{INVASIVE AND NON-INVASIVE THERAPY}

The optimal management of patients with CAE is largely unknown. The uncertainties regarding the natural history of $\mathrm{CAE}$ and the absence of robust randomized and large-scale data complicate the resolution of this clinical conundrum. Moreover, the most relevant amount of the current evidence on the treatment of CAE has been extracted from cohorts of symptomatic patients, often with ACS as clinical presentation, but conversely a lack of data on asymptomatic patients with incidentally found CAE and no evidence of significant CAD exists. Possible treatment options include medical therapy, PCI, and surgery, but each of these strategies reserves technical and clinical challenges. In absence of specific recommendations, management strategies are still individually tailored according to clinical presentation, anatomical features, and procedural complexity.

Figure 5 summarizes the clinical management of patients with CAE.

\section{Percutaneous Interventions}

Percutaneous treatment of CAE is a valuable option in patients with suitable anatomical and clinical features. However, PCI of ectatic and aneurysmatic lesions presents several challenges, starting from lack of specific indications. First, it is uncertain whether conservative or interventional strategy is to be preferred in CAE patients without obstructive CAD, and there is no supportive evidence on PCI outcomes in this setting. Nonetheless, in patients with CAE and significant coronary stenoses and/or ACS, PCI has several technical challenges that must be carefully balanced into decision-making process when considering the optimal revascularization strategy. In the setting of an ACS with an EIRA, high thrombus burden with distal embolization and microvascular damage substantially increases the technical complexity of PCI, with a high risk of procedural failure and adverse events at long term (70). Given the high thrombus load, several reports showed a wider use of glycoprotein IIb/IIIa inhibitors and thrombus aspiration in patients treated with primary PCI of an $\operatorname{EIRA}(7,72,83)$. Despite these efforts, distal embolization with impairment of epicardial 
TABLE 1 | Main studies evaluating clinical outcome in patients with CAE.

\begin{tabular}{|c|c|c|c|c|c|}
\hline References & $\begin{array}{l}\text { No. of CAE } \\
\text { patients }\end{array}$ & $\begin{array}{l}\text { CAE } \\
\text { phenotype }\end{array}$ & Clinical setting & Primary outcomes & Results \\
\hline Baldi et al. (7) & 154 & $\begin{array}{l}\text { All CAE } \\
\text { phenotypes }\end{array}$ & STEMI & $\begin{array}{l}\text { Recurrence of Ml compared with } 380 \\
\text { controls at } 1,218.3 \pm 574.8 \text { days of } f / u\end{array}$ & $\begin{array}{l}\text { Higher recurrence of } \mathrm{Ml} \text { in CAE patients } \\
\text { (HR 1.84; } 95 \% \mathrm{Cl} 1.11-3.05 ; p=0.017)\end{array}$ \\
\hline Will et al. (76) & 81 & $\begin{array}{l}\text { All CAE } \\
\text { phenotypes }\end{array}$ & $\begin{array}{l}\text { STEMI } \\
\text { NSTEMI } \\
\text { CCS }\end{array}$ & $\begin{array}{l}\text { MACE in patients with CAA treated with } \\
\text { covered stent }\end{array}$ & $\begin{array}{l}\text { The use of covered stents for elective } \\
\text { treatment of CAA is effective and } \\
\text { reasonably safe }\end{array}$ \\
\hline Wang et al. (74) & 174 & $\begin{array}{l}\text { All CAE } \\
\text { phenotypes }\end{array}$ & $\begin{array}{l}\text { STEMI } \\
\text { NSTEMI }\end{array}$ & $\begin{array}{l}\text { MACE compared with } 4,614 \text { non-CAE } \\
\text { patients at a median f/u of } 4 \text { years }(1-7)\end{array}$ & $\begin{array}{l}\text { CAE is associated with higher recurrence } \\
\text { of MACE (HR 1.597; 95\% Cl 1.238-2.060; } \\
p<0.001 \text { ) }\end{array}$ \\
\hline $\begin{array}{l}\text { Khubber et al. } \\
(77)\end{array}$ & 458 & Only CAAs & $\begin{array}{l}\text { All comers patients } \\
\text { undergoing ICA }\end{array}$ & $\begin{array}{l}\text { MACCE in patients treated with medical } \\
\text { therapy (230), PCI (52), or CABG (176) at a } \\
\text { median f/u of } 62 \text { months (11-120) }\end{array}$ & $\begin{array}{l}\text { Similar long-term outcomes in patients } \\
\text { with CAA undergoing medical, } \\
\text { percutaneous, and surgical management } \\
\text { (OR } 0.773 ; 0.526-1.136 ; p=0.19 \text { ) }\end{array}$ \\
\hline Cai et al. (75) & 595 & $\begin{array}{l}\text { All CAE } \\
\text { phenotypes }\end{array}$ & $\begin{array}{l}\text { All comers patients } \\
\text { undergoing ICA }\end{array}$ & $\begin{array}{l}\text { MACE during a median } f / u \text { of } 87 \text { months } \\
(72-104)\end{array}$ & $\begin{array}{l}\text { Higher risk of MACE in patients with } \\
\text { diffuse CAE than focal CAE (HR 3.26, 95\% } \\
\text { Cl 1.17-9.04, } p=0.023 \text { ) }\end{array}$ \\
\hline $\begin{array}{l}\text { D'Ascenzo et al. } \\
\text { (78) }\end{array}$ & 585 & Only CAAs & $\begin{array}{l}\text { All comers patients } \\
\text { undergoing ICA }\end{array}$ & $\begin{array}{l}\text { Composite of MI, } \mathrm{UA} \text {, and aneurysm } \\
\text { thrombosis compared to } 390 \text { control } \\
\text { patients at a median } \mathrm{f} / \mathrm{u} \text { of } 3 \text { years }(1-7)\end{array}$ & $\begin{array}{l}\text { OAC decreases the composite endpoint } \\
(8.7 \text { vs. } 17.2 \% ; p=0.01) \text {, non-significant } \\
\text { higher risk of bleeding }\end{array}$ \\
\hline $\begin{array}{l}\text { Nuñez-Gil et al. } \\
\text { (6) }\end{array}$ & 1,565 & Only CAAs & $\begin{array}{l}\text { All comers patients } \\
\text { undergoing ICA }\end{array}$ & $\begin{array}{l}\text { Composite of MI, } \mathrm{UA} \text {, and aneurysm } \\
\text { thrombosis compared with } 380 \text { control } \\
\text { patients at a median } \mathrm{f} / \mathrm{u} \text { of } 3 \text { years }(1-7)\end{array}$ & $\begin{array}{l}\text { OAC decreases the composite endpoint } \\
(8.7 \text { vs. } 17.2 \% ; p=0.01) \text {, non-significant } \\
\text { higher risk of bleeding }\end{array}$ \\
\hline $\begin{array}{l}\text { Gunasakeran et } \\
\text { al. (9) }\end{array}$ & 317 & $\begin{array}{l}\text { All CAE } \\
\text { phenotypes }\end{array}$ & $\begin{array}{l}\text { All comers patients } \\
\text { undergoing ICA }\end{array}$ & $\begin{array}{l}\text { Long-term CV and survival outcomes at a } \\
\text { mean f/u of } 9.4 \pm 1.8 \text { years }\end{array}$ & $\begin{array}{l}\text { Diffuse CAE and TIMI flow }<3 \text { are } \\
\text { independent predictors of ACS (OR 4; } \\
95 \% \mathrm{Cl} 2.0-7.8 ; p<0.01 \text { ); DAPT (17 vs. } \\
34 \% ; p=0.03 \text { ) or OAT ( } 29 \text { vs. } 42 \% ; p= \\
0.02 \text { ) reduce the risk of ACS }\end{array}$ \\
\hline $\begin{array}{l}\text { Schram et al. } \\
\text { (79) }\end{array}$ & 77 & $\begin{array}{l}\text { All CAE } \\
\text { phenotypes }\end{array}$ & STEMI & $\begin{array}{l}\text { CAE as independent predictor of no-reflow } \\
\text { compared with } 154 \text { controls }\end{array}$ & $\begin{array}{l}\text { CAE independent predictor of no-reflow } \\
\text { (OR 13.9; } 95 \% \mathrm{Cl} 4.7-41.2, p<0.001 \text { ) }\end{array}$ \\
\hline $\begin{array}{l}\text { Shanmugam et } \\
\text { al. (70) }\end{array}$ & 25 & $\begin{array}{l}\text { All CAE } \\
\text { phenotypes }\end{array}$ & STEMI & $\begin{array}{l}\text { MACE in patients with EIRA compared } \\
\text { with } 80 \text { controls at a mean f/u of } 36.6 \pm \\
14.1 \text { months }\end{array}$ & $\begin{array}{l}\text { EIRA patients had higher long-term } \\
\text { incidence of composite CV events ( } 44.0 \\
\text { vs. } 16.3 \% ; p=0.01 \text { ) }\end{array}$ \\
\hline $\begin{array}{l}\text { lannopollo et al. } \\
\text { (80) }\end{array}$ & 32 & Only CAAs & STEMI & $\begin{array}{l}\text { Composite of all-cause death and } \\
\text { recurrent } \mathrm{Ml} \text { compared with } 2,280 \text { controls } \\
\text { at } 30 \text { days and } 1 \text { year } \mathrm{f} / \mathrm{u}\end{array}$ & $\begin{array}{l}\text { CAA as culprit lesion associated with } \\
\text { death and recurrent } \mathrm{Ml}(\mathrm{HR} 2.24,95 \% \mathrm{Cl} \\
1.02-5.39, p=0.04) \text { and with ST (HR } \\
6.29,95 \% \mathrm{Cl} 2.32-17.05, p<0.001)\end{array}$ \\
\hline Doi et al. (8) & 51 & $\begin{array}{l}\text { All CAE } \\
\text { phenotypes }\end{array}$ & $\begin{array}{l}\text { STEMI } \\
\text { NSTEMl }\end{array}$ & $\begin{array}{l}\text { MACE compared with } 1,647 \text { controls at a } \\
\text { median f/u of } 49 \text { months (19-93) }\end{array}$ & $\begin{array}{l}\text { CAE associated with higher risk of MACE } \\
\text { (HR 4.94; } 95 \% \mathrm{Cl}, 2.36-10.4 ; p<0.001 \text { ). } \\
\text { No MACE in patients receiving OAT with } \\
\% T R \geq 60 \%\end{array}$ \\
\hline $\begin{array}{l}\text { Nuñez-Gil et al. } \\
\text { (81) }\end{array}$ & 256 & Only CAAs & $\begin{array}{l}\text { STEMI } \\
\text { NSTEMI }\end{array}$ & $\begin{array}{l}\text { MACE compared with } 500 \text { controls at } \\
\text { median f/u of } 52 \text { months }(27-84)\end{array}$ & $\begin{array}{l}\text { Higher mortality (HR 3.1; 95\% Cl: 1.8-5.6; } \\
p<0.01 \text { ) and MACE (HR 2.3; 95\% Cl: } \\
1.4-3.8 ; p<0.01 \text { ) in patients with CAA }\end{array}$ \\
\hline Ipek et al. (72) & 99 & $\begin{array}{l}\text { All CAE } \\
\text { phenotypes }\end{array}$ & STEMI & $\begin{array}{l}\text { Short and long-term ( } 1 \text { year) outcomes } \\
\text { compared with 1,556 controls }\end{array}$ & $\begin{array}{l}\text { Higher rates of no-reflow in EIRA (13.1 vs. } \\
5.4 \%, p=0.004 \text { ) in patients. } \\
\text { Non-significant differences in mortality }\end{array}$ \\
\hline $\begin{array}{l}\text { Campanile et al. } \\
\text { (82) }\end{array}$ & 101 & $\begin{array}{l}\text { All CAE } \\
\text { phenotypes }\end{array}$ & STEMI & Short and long-term (2 years f/u) MACE & $\begin{array}{l}\text { MACE in } 6.9 \% \text { cases during hospitalization } \\
\text { in } 17.8 \% \text { at } 1 \text { year, and in } 38.5 \% \text { at } 2 \\
\text { years. } 8.9 \% \text { of patients had a ST. }\end{array}$ \\
\hline Erden et al. (73) & 31 & $\begin{array}{l}\text { All CAE } \\
\text { phenotypes }\end{array}$ & STEMI & $\begin{array}{l}\text { Recurrence of MACE at short and } \\
\text { long-term f/u compared with } 612 \text { controls }\end{array}$ & $\begin{array}{l}\text { EIRA is an independent predictor of } \\
\text { adverse outcome (OR 0.197; } 95 \% \mathrm{Cl} \\
0.062-0.633 ; p=0.006)\end{array}$ \\
\hline Baman et al. (69) & 276 & Only CAAs & $\begin{array}{l}\text { All comers patients } \\
\text { undergoing ICA }\end{array}$ & $\begin{array}{l}\text { Mortality at } 5 \text { years } \mathrm{f} / \mathrm{u} \text { compared with } 550 \\
\text { controls }\end{array}$ & $\begin{array}{l}\text { CAA associated with mortality (HR } 1.56 \text {; } \\
95 \% \text { Cl } 1.01-2.41 ; p=0.04 \text { ) }\end{array}$ \\
\hline
\end{tabular}


TABLE 1 | Continued

\begin{tabular}{|c|c|c|c|c|c|}
\hline References & $\begin{array}{l}\text { No. of CAE } \\
\text { patients }\end{array}$ & $\begin{array}{l}\text { CAE } \\
\text { phenotype }\end{array}$ & Clinical setting & Primary outcomes & Results \\
\hline $\begin{array}{l}\text { Demopoulos et } \\
\text { al. (18) }\end{array}$ & 203 & $\begin{array}{l}\text { All CAE } \\
\text { phenotypes }\end{array}$ & $\begin{array}{l}\text { All comers patients } \\
\text { undergoing ICA }\end{array}$ & MACE at 2 years f/u & $\begin{array}{l}\text { CAE does not confer additional risk in } \\
\text { patients with coexisting CAD }\end{array}$ \\
\hline Swaye et al. (1) & 978 & $\begin{array}{l}\text { All CAE } \\
\text { phenotypes }\end{array}$ & $\begin{array}{l}\text { All comers patients } \\
\text { undergoing ICA }\end{array}$ & $\begin{array}{l}\text { Survival at } 5 \text { years f/u compared with } \\
15,249 \text { controls }\end{array}$ & $\begin{array}{l}\text { No difference in survival was noted } \\
\text { between CAE/CAA patients and } \\
\text { non-CAE/CAA ones. }\end{array}$ \\
\hline
\end{tabular}

\%TTR, percent time in target therapy range; ACS, acute coronary syndrome; AMI, acute myocardial infarction; CAA, coronary artery aneurysm; CABG, coronary artery bypass grafting; CAE, coronary artery ectasia; CCS, chronic coronary syndrome; DAPT, dual antiplatelet therapy; EIRA, ectatic infarct-related artery; f/u, follow-up; HR hazard ratio; ICA, invasive coronary angiography; MACCE, major adverse cardiovascular and cerebral events; MACE, major adverse cardiovascular events; MI, myocardial infarction; NSTEMI, non-ST-elevation myocardial

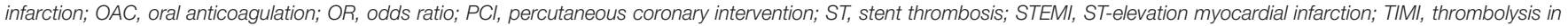
myocardial infarction; UA, unstable angina.

flow and/or microcirculatory reperfusion is frequently reported in these patients $(73,82)$. In a case-control study on 231 STEMI patients with and without CAE, Schram et al. found that CAE was an independent predictor of no-reflow after primary PCI (79). In selected cases of extensive thrombus burden and high risk of no-reflow, deferring stenting after an aggressive antithrombotic therapy may be an option. However, current evidence suggests that deferred stenting might be considered only in selected subsets of STEMI patients with high-risk anatomical features and to date there is no evidence in patients with $\operatorname{CAE}(84,85)$.

Besides procedural complications, previous data showed that the presence of a CAA is a risk factor for stent thrombosis (ST) after PCI in patients with ACS (86). Iannopollo et al. assessed the 1-year clinical outcome of STEMI patients treated with primary PCI of a culprit lesion involving a CAA, and found that patients with an aneurysmal culprit had a higher recurrence of MI compared to those without, mainly driven by more definite ST (80). Several factors may explain the high risk of ST in CAE, including residual thrombus, flow disturbances and stent malapposition. Indeed, adequate stent sizing is one of the major challenges of PCI in CAE, even in non-ACS patients (87). Coronary angiography has some limitations in the visualization of aneurysmatic and ectatic segments in the deeper part of their lumen, especially in presence of endoluminal thrombotic material that might underestimate the true size of the vessel. Moreover, delayed antegrade contrast filling and dye stasis might further complicate the angiographic assessment of these lesions, and a prolongation of both contrast media injection and X-ray acquisition may be needed. Besides malapposition and thrombosis, inadequate stent sizing might also be associated with stent displacement and migration, especially in case of giant CAAs $(87,88)$. Assessment of lesion length and landing zone identification may also be difficult and often multiple overlapping stents are required to fully cover the diseased segments (89). The use of IVUS for PCI guidance appears to be mandatory to better define vessel architecture and provide accurate information for stent sizing and optimization, in order to reduce the risk of malapposition and ST (90). OCT may also be helpful, especially for a better assessment of thrombotic lesions and plaque morphology, but its application in CAE is limited by the incomplete blood clearance and low penetration depth in large vessels.
In consideration of these technical challenges, if PCI is clinically indicated, different percutaneous techniques should be adapted to the anatomical scenario. Exclusion with covered stents might be indicated in saccular CAAs or small pseudoaneurysms not involving major side branches (11). Figure 6 illustrates a case showing the successful covered stent exclusion of a saccular CAA in the distal RCA with high thrombus burden. Different covered stents are currently available, but GRAFTMASTER (Abbott Vascular, Santa Clara, California) and PK Papyrus (Biotronik, Berlin, Germany) are the most frequently used. The GRAFTMASTER is constructed using a sandwich technique, with an ultra-thin layer of expandable polytetrafluoroethylene (PTFE) placed between 2 stainless steel stents, which are then pre-mounted on a balloon catheter delivery system. The stent can be used from diameters ranging from 2.8 to $5.5 \mathrm{~mm}$ and can be delivered through a 6 or 7 Fr guiding catheter, depending on the size of the device. PK Papyrus is a new-generation cobalt chromium single covered stent. Because of its advanced single stent design, it has greater bending flexibility and smaller crossing profile compared to GRAFTMASTER and can be delivered through a 5 or 6 Fr guiding catheter. For diameters from $5.5 \mathrm{~mm}$ to $10 \mathrm{~mm}$ the Atrium iCAST balloon expandable covered stent (MAQUET, Wayne, New Jersey) can be used, but an 8 or 9 Fr guiding catheter is needed. However, the use of covered stents is limited by several technical issues: the stiffness of the device, the poor deliverability and the need for large sheaths and guiding catheters are associated with a higher risk of procedural complications, especially in severely tortuous and calcified vessels. Moreover, the risk of side branch loss represents one the major limitation of covered stents. Different techniques have been described to avoid major side branches loss during covered stent implantation. GRAFTMASTER is a one-size stent mounted on different sized balloons and therefore its skirt can be shortened by $\sim 3 \mathrm{~mm}$ with high-pressure post-dilatation using large non-compliant balloons: this technique allows to fully cover short CAAs, without landing at the level of major side branches $(91,92)$. Recently Davies et al. described a novel technique to treat large CAAs involving bifurcations with large side branches: first, a PK Papyrus is implanted from the proximal to the distal main vessel; second, a stiff guidewire with high tip load supported by a microcatheter is used to puncture across covered stent into the side branch; third, the microcatheter is advanced through the PK 


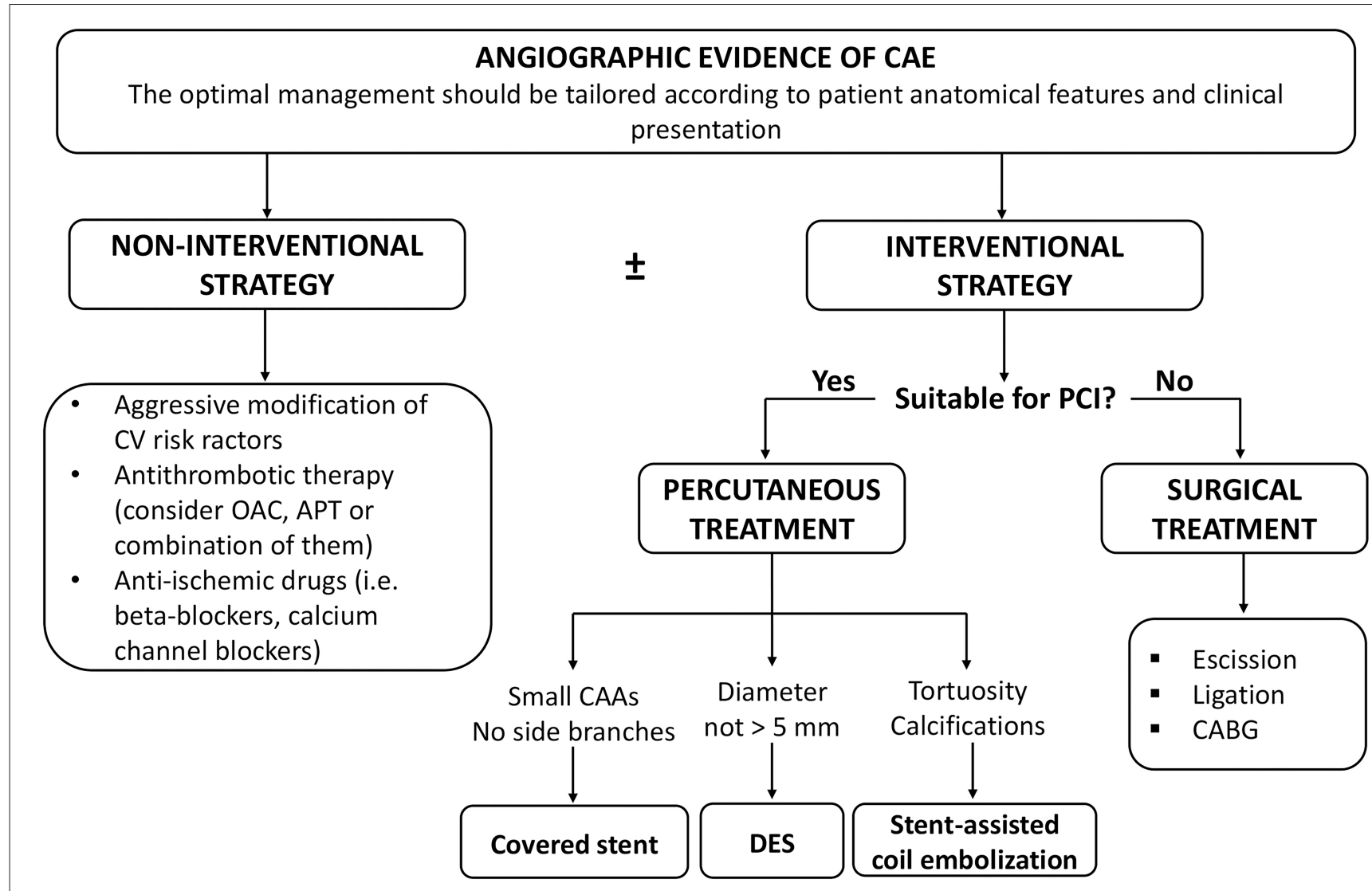

FIGURE 5 | Clinical management of patients with CAE. APT, antiplatelet therapy; CAAs, coronary artery aneurysms; CABG, coronary artery bypass grafting; CAE, coronary artery ectasia; CV, cardiovascular; DES, drug-eluting stent; OAC, oral anticoagulation; PCl, percutaneous coronary intervention.

Papyrus to enlarge the opening and is used to exchange the stiff wire with a regular workhorse; Excimer laser atherectomy is then performed to ablate the polyurethane membrane of the covered stent at the level of the ostium of the side branch; finally, the PK Papyrus stent strut can be dilated with single balloon and double kissing balloon inflations (93). A similar fenestration technique of PK Papyrus without the use of excimer laser, has been carried out to gain access to the LAD in a case of covered stent implantation from the LM to the LCx for a perforation of the ostial LCx (94). However, these cases remain anecdotal and are not supported by data from observational studies; therefore, similar techniques should be limited to bail-out situations in specific anatomical settings and should be performed by experienced operators in complex PCI. Furthermore, in large CAAs involving major bifurcations, not suitable for percutaneous treatment, $\mathrm{CABG}$ remains a valuable option.

Beyond procedural technicalities, another limitation of covered stents is the high risk of ISR and ST at long-term follow up, with a substantial higher risk of target lesion revascularization (TLR) compared to new-generation DES (9598). The underlying mechanisms are multifactorial and include impaired vascular healing, pro-thrombotic activation induced by the surface of stent material and neointimal proliferation at the edges of the covered stents caused by vessel trauma due to high-pressure balloon dilatations (99, 100). Recently Bossard et al. described a novel hybrid approach whereby the covered stent is "buried" with over-stenting and implantation of a new-generation DES, in order to benefit from its antiproliferative drugs and modern technology: the authors assessed the clinical outcome of 23 patients treated with this technique and showed low incidence of adverse events at long-term follow up, with low rate of TLR and no cases of ST (101). However, these results should be interpreted with caution because of the small number of patients evaluated, and should be confirmed in larger cohorts of patients treated with covered stent implantation.

In cases where covered stent implantation is not possible due to severe tortuosity, calcifications or fear of side branch loss, stent-assisted coil embolization can be used, especially in large CAAs with wide neck. With this technique, commonly used in the treatment of cerebral aneurysms, a floppy guidewire supported by a microcatheter is directed inside the CAA before stent implantation. A coronary stent covering the entire neck of the CAA is then deployed at low pressure, jailing the microcatheter into the CAA; coils can then be passed through the microcatheter to wrap around the stent. Post-dilation of the stent is securely performed, after the microcatheter removal. Additional coils can be advanced through the stent struts if needed (102). There are several potential complications that 

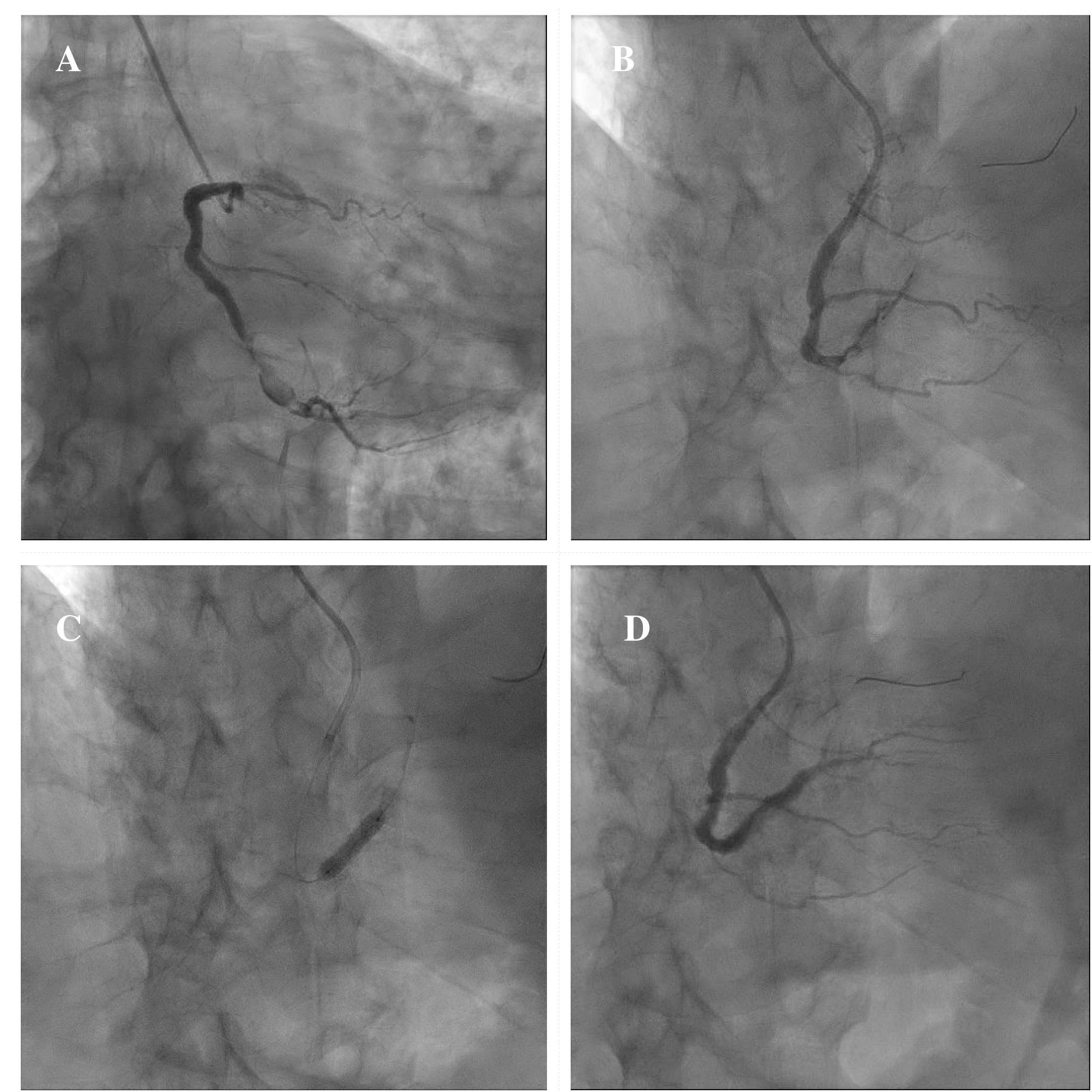

FIGURE 6 | Example of exclusion of a saccular CAA in the distal RCA with high thrombus burden by means of covered stent implantation. Severe ISR of a previously implanted DES in the distal segment of the RCA continuing in a saccular CAA with high thrombus burden (A). A $3.5 \times 15$ mm PK Papyrus covered stent is advanced to precisely seal the inlet and outlet of the CAA (B). A DES Synergy (Boston Scientific, Marlborough, Massachusetts) $4 \times 24$ mm is then implanted proximally to the covered stent to treat the severe ISR (C). Final result showing the exclusion of the saccular CAA (D). CAA, coronary artery aneurysm; DES, drug-eluting stent; ISR, in-stent restenosis; RCA, right coronary artery.

should be considered during the procedure: the weakness of the aneurysmatic wall increases the risk of rupture during the embolization, therefore microcatheters, wires and coils should be manipulated with caution; another potential complication is coil herniation through the stent struts that may lead to acute or late stent thrombosis (103). Figure 7 illustrates a case showing a hybrid approach with stent-assisted coil embolization and covered stent implantation for the treatment of an iatrogenic dual-chamber pseudoaneurysm following PCI of the proximal LAD.

Percutaneous interventions are a valuable option for the treatment of SVGAs, especially in patients with high surgical risk 


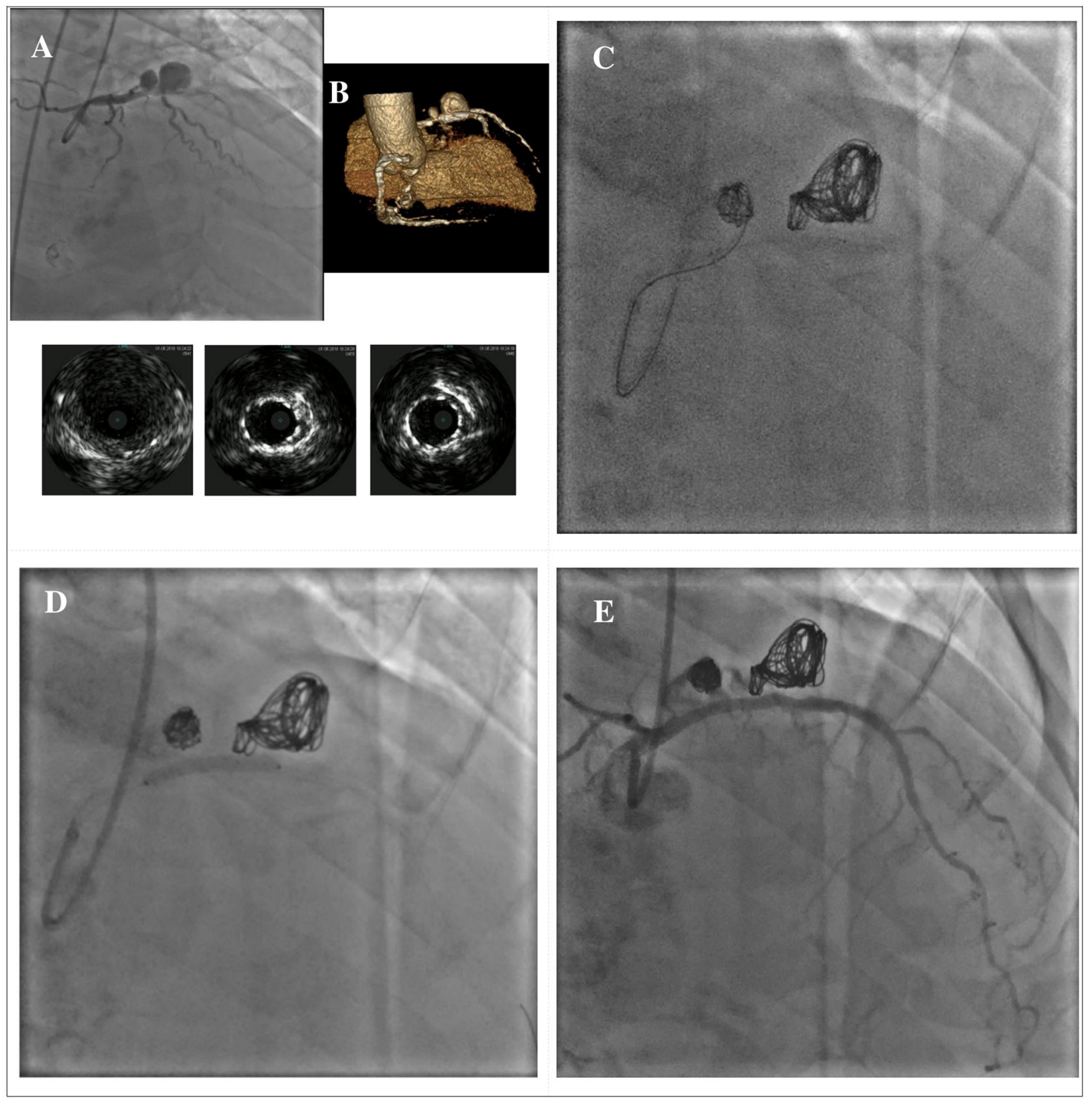

FIGURE 7 | Hybrid approach for combined treatment with stent-assisted coil embolization and covered stent implantation in a dual-chamber iatrogenic pseudoaneurysm following PCl of the proximal LAD. The upper panel shows the angiographical view of an iatrogenic pseudoaneurysm of the proximal LAD due to a previous PCI with DES implantation; the lower panel shows the IVUS images of the pseudoaneurysm and its relationship with the previously implanted DES (A). Rendered volume CCTA image showing a large dual-chamber pseudoaneurysm (B). Multiple coils are advanced through a microcatheter to wrap around the old DES until completely filling both cavities of the pseudoaneurysm (C). A BeGraft covered stent (Bentley InnoMed, Hechingen, Germany) $3 \times 24$ mm has been used to secure the coils correct positioning (D). Final result (E). *Courtesy of Dr. Fabio Felice Tarantino. CCTA, coronary computed tomography angiography; DES, drug-eluting stent; IVUS, intravascular ultrasound; LAD, left anterior descending; $\mathrm{PCl}$, percutaneous coronary intervention.

and/or with preserved myocardial perfusion. These techniques have been increasingly used in recent years and include covered stent implantation, percutaneous closure with Amplatzer occluders and coil embolization with or without PCI of the native grafted vessel (57).

\section{Surgical Treatment}

There is lack of robust evidence on the surgical treatment of CAE. Possible surgical techniques include CAA resection, ligation, or marsupialization with bypass grafting (104-106). However, there is uncertainty regarding the indications for 
surgery in patients with CAE. Khubber et al. in a singlecenter retrospective unadjusted study on 458 patients with CAA, found no significant differences in terms of adverse cardiovascular and cerebrovascular events between patients treated with CABG or PCI (77). Similar results were reported in 1,565 patients from the international coronary artery aneurysm registry (CAAR), with no differences in terms of adverse cardiovascular events and mortality between patients treated with either surgical or percutaneous approach (6). According to these findings, surgical treatment of CAE should be considered as the first-line therapy in cases where PCI is deemed to be at high risk due to complex anatomical features, like for CAAs involving the LM, multiple or giant CAAs, and SVGAs with graft thrombosis, impaired myocardial perfusion and acute mechanical complications $(11,57)$.

\section{Medical Therapy}

The optimal medical therapy of patients with CAE is an area of ongoing debate. Considering that atherosclerosis is involved in the pathogenesis of CAE in most cases, an aggressive modification of cardiovascular risk factors should be mandatory in these patients.

However, antithrombotic therapy is the most controversial issue on the pharmacological treatment of CAE. Severe coronary dilatation is associated with flow disturbances and blood stasis, thus predisposing to the activation of coagulation cascade with increased risk of local thrombosis and distal embolization $(18,107)$. Moreover, an increased platelet reactivity has been described in patients with CAE (108). Given these pathophysiological considerations, oral anticoagulation (OAC) and prolonged dual antiplatelet therapy (DAPT) have been proposed as possible therapeutic strategies in these patients (11). However, literature provide only limited and conflictual evidence on this topic, especially in asymptomatic patients with incidentally found CAE. The need for a tailored pharmacological approach with aggressive antithrombotic regimens is justified by the growing evidence of a high risk of cardiovascular events in patients with CAE, especially in the setting of an ACS (7, $8,74,109)$. Doi et al. found that among 51 CAE patients with $\mathrm{MI}$, those who received $\mathrm{OAC}$ and reached a time-in-target therapeutic range $\geq 60 \%$ did not experience major cardiovascular events at 49 months follow-up (8). Similarly, Gunasakeran et al. showed a lower incidence of recurrent ACS at long term in CAE patients treated with DAPT or OAC compared to those not receiving these treatments (9). Furthermore, in a propensity-matched analysis on 585 patients with CAAs from the CAAR registry, OAC significantly reduced the incidence of the composite endpoint of UA, MI and CAA thrombosis, with a nonsignificant increase in bleedings, mainly classified as Bleeding Academic Research Consortium type 1 (78).

However, because of the observational design and the relatively small sample size of these studies, these data should be interpreted with caution and should be confirmed by dedicated randomized trials or large multicentre registries.

In patients with $\mathrm{KD} \mathrm{OAC}$ is recommended in selected patients with large and/or rapidly expanding CAAs (12). Moreover, intravenous administration of immunoglobulins in the acute phase is associated with high rates of CAA regression in these patients (42).

Given the role of atherosclerosis, inflammation and endothelial disfunction in the pathogenesis of CAE, statins and ACE-inhibitors have been proposed as possible therapeutic options due to their pleiotropic effects on the endothelium (110). Fan et al. evaluated the anti-inflammatory effects of rosuvastatin in patients with CAE, and found that levels of inflammatory biomarkers were significantly reduced after 6 months of treatment, especially in younger patients (111). Another study on 152 patients with CAE showed that polymorphism of the ACE gene, associated with a higher expression and activity of the enzyme, is independently associated with CAE (112). However, in absence of long-term studies, these data remain speculative.

Several anti-ischemic drugs have been proposed as possible therapeutic options in patients with CAE. Krüger et al. showed that the development of inducible ischemia in CAE depended on heart rate (5). Therefore, $\beta$-blockers $(\beta-B)$ might be a reasonable option due to their negative chronotropic effect and reduction of myocardial oxygen demand in the absence of vasodilation (113). However, the use of $\beta$-B in patients with CAE has been questioned due to the risk of coronary spasm related to the unopposed $\alpha$-receptors' stimulation (114).

Unlike $\beta$-B, calcium channel blockers (CCB) have anti-spastic effects and might have a beneficial role by reducing the risk of coronary spasm and thrombus formation (114). Other possible anti-ischemic effects of $\mathrm{CCB}$ in $\mathrm{CAE}$ include improvement of coronary blood flow and myocardial perfusion, and antihypertensive effects $(18,115)$.

Trimetazidine can also improve coronary flow and myocardial preconditioning by increasing adenosine levels, and showed to reduce exercise-induced myocardial ischemia in patients with CAE (116).

Unlike patients with CAD, nitrates should be avoided in patients with CAE because of their promotion of flow disturbances and exacerbation of myocardial ischemia (5).

\section{GAPS IN KNOWLEDGE AND FUTURE DIRECTIONS}

Despite growing evidence on CAE in recent years, several controversies remain about its natural history and treatment. Although several studies showed a poor outcome in patients with ACS and angiographic evidence of CAE, the risk of future adverse events in asymptomatic patients with isolated CAE and nonobstructive CAD is unknown. Due to the absence of data from large multicenter studies and of specific recommendations, there is great uncertainty on what is the best medical and interventional treatment of isolated CAE.

In patients with obstructive $\mathrm{CAD}$ and indication for PCI, there are several procedural issues: (1) The use of intravascular imaging during PCI might be helpful for stent sizing and landing zone identification, but the large caliber may affect the quality of images, particularly for OCT; (2) The high thrombus burden in the setting of an ACS is associated with a higher risk of no-reflow, but the optimal periprocedural 
antithrombotic therapy has not been clarified yet; (3) The technology advances in interventional cardiology have provided several options for the percutaneous treatment of patients with CAE (i.e., DES, covered stents, coil embolization); however, the long-term performance of these devices needs to be investigated; (4) Optimal antithrombotic therapy is another missing piece in the complex framework of CAE; OAC and long-term DAPT have been proposed as possible therapeutic options, but the evidence is still controversial and limited to small number of patients.

Moreover, given atherosclerosis as the most prevalent underlying condition, it is unknown whether aggressive lipid lowering therapies with PCSK-9 inhibitors might provide a prognostic benefit in CAE patients with ACS. Lipoprotein (a) $[\mathrm{Lp}(\mathrm{a})]$, despite being associated with aortic and cerebral aneurysms, has an unclear role in the pathogenesis of CAE (117119). In consideration of the association between high $\mathrm{Lp}(\mathrm{a})$ levels and adverse cardiac events in patients with CAD, Lp(a) might be a useful predictor for the prognostic stratification of CAE (120-122).

The renovated interest in CAE in the recent years emphasizes the crucial role of some required improvements in its knowledge pathway: the importance of a unique shared definition, of a deeper characterization of CAE phenotypes in real-world registries, and of effective therapies in randomized trials.

\section{REFERENCES}

1. Swaye PS, Fisher LD, Litwin P, Vignola PA, Judkins MP, Kemp HG, et al. Aneurysmal coronary artery disease. Circulation. (1983) 67:134-8. doi: 10.1161/01.CIR.67.1.134

2. Hartnell GG, Parnell BM, Pridie RB. Coronary artery ectasia. Its prevalence and clinical significance in 4993 patients. Br Heart J. (1985) 54:392-5. doi: 10.1136/hrt.54.4.392

3. Antoniadis AP, Chatzizisis YS, Giannoglou GD. Pathogenetic mechanisms of coronary ectasia. Int J Cardiol. (2008) 130:335-43. doi: 10.1016/j.ijcard.2008.05.071

4. Alfonso F, Pérez-Vizcayno MJ, Ruiz M, Suárez A, Cazares M, Hernández $\mathrm{R}$, et al. Coronary aneurysms after drug-eluting stent implantation: clinical, angiographic, and intravascular ultrasound findings. J Am Coll Cardiol. (2009) 53:2053-60. doi: 10.1016/j.jacc.2009.01.069

5. Krüger D, Stierle U, Herrmann G, Simon R, Sheikhzadeh A. Exerciseinduced myocardial ischemia in isolated coronary artery ectasias and aneurysms (“dilated coronopathy"). J Am Coll Cardiol. (1999) 34:1461-70. doi: 10.1016/S0735-1097(99)00375-7

6. Núñez-Gil IJ, Cerrato E, Bollati M, Nombela-Franco L, Terol B, AlfonsoRodríguez E, et al. Coronary artery aneurysms, insights from the international coronary artery aneurysm registry (CAAR). Int J Cardiol. (2020) 299:49-55. doi: 10.1016/j.ijcard.2019.05.067

7. Baldi C, Silverio A, Esposito L, Di Maio M, Tarantino F, De Angelis E, et al. Clinical outcome of patients with ST-elevation myocardial infarction and angiographic evidence of coronary artery ectasia. Catheter Cardiovasc Interv. (2021). doi: 10.1002/ccd.29738. [Epub ahead of print].

8. Doi T, Kataoka Y, Noguchi T, Shibata T, Nakashima T, Kawakami S, et al. Coronary artery ectasia predicts future cardiac events in patients with acute myocardial infarction. Arterioscler Thromb Vasc Biol. (2017) 37:2350-5. doi: 10.1161/ATVBAHA.117.309683

9. Gunasekaran P, Stanojevic D, Drees T, Fritzlen J, Haghnegahdar M, McCullough $\mathrm{M}$, et al. Prognostic significance, angiographic characteristics and impact of antithrombotic and anticoagulant therapy on outcomes in

\section{CONCLUSIONS}

CAE, defined as a diffuse or focal dilatation of an epicardial coronary artery, is reported in up to $5 \%$ of patients undergoing coronary angiography. The clinical manifestations of CAE are heterogeneous, ranging from asymptomatic cases to high-risk patients with ACS (17). There is growing evidence of an increased risk of adverse events at long term in patients with CAE, especially in those with ACS $(7,8)$. The management of these patients is challenging, and treatment options include optimal antithrombotic therapy, surgery, and percutaneous interventions with DES implantation, covered stent exclusion or stent-assisted coil embolization (11). Despite a deeper understanding of CAE in recent years, there are still come critical issues about is natural history and treatment that need to be address. Large multicenter studies are warranted to guide the clinician in the management of this complex setting of patients.

\section{AUTHOR CONTRIBUTIONS}

LE, MD, FC, and MB: drafting of the manuscript. AS, TA, FT, and GE: revising critically the manuscript. $\mathrm{CB}, \mathrm{CV}$, and GG: final approval of the manuscript. All authors contributed to the article and approved the submitted version.

high versus low grade coronary artery ectasia: a long-term follow-up study. Catheter Cardiovasc Interv. (2019) 93:1219-27. doi: 10.1002/ccd.27929

10. Syed M, Lesch M. Coronary artery aneurysm: a review. Progr Cardiovasc Dis. (1997) 40:77-84. doi: 10.1016/S0033-0620(97)80024-2

11. Kawsara A, Núñez Gil IJ, Alqahtani F, Moreland J, Rihal CS, Alkhouli M. Management of coronary artery aneurysms. JACC Cardiovasc Interv. (2018) 11:1211-23. doi: 10.1016/j.jcin.2018.02.041

12. McCrindle BW, Rowley AH, Newburger JW, Burns JC, Bolger AF, Gewitz $M$, et al. Diagnosis, treatment, and long-term management of kawasaki disease: a scientific statement for health professionals from the American Heart Association. Circulation. (2017) 135:e927-99. doi: 10.1161/CIR.0000000000000484

13. Maehara A, Mintz GS, Ahmed JM, Fuchs S, Castagna MT, Pichard $\mathrm{AD}$, et al. An intravascular ultrasound classification of angiographic coronary artery aneurysms. Am J Cardiol. (2001) 88:365-70. doi: 10.1016/S0002-9149(01)01680-0

14. Hassan A, Uretsky BF, Vargas Estrada AM, Hassan R, Al-Hawwas M, Agarwal SK. Systematic review of the evaluation and management of coronary pseudoaneurysm after stent implantation. Catheter Cardiovasc Interv. (2021) 98:107-16. doi: 10.1002/ccd.29312

15. Kar S, Webel RR. Diagnosis and treatment of spontaneous coronary artery pseudoaneurysm: rare anomaly with potentially significant clinical implications. Catheter Cardiovasc Interv. (2017) 90:589-97. doi: $10.1002 / \mathrm{ccd} .26997$

16. Markis JE, Joffe CD, Cohn PF, Feen DJ, Herman MV, Gorlin R. Clinical significance of coronary arterial ectasia. Am J Cardiol. (1976) 37:217-22. doi: 10.1016/0002-9149(76)90315-5

17. Abou Sherif S, Ozden Tok O, Taşköylü Ö, Goktekin O, Kilic ID. Coronary artery aneurysms: a review of the epidemiology, pathophysiology, diagnosis, and treatment. Front Cardiovasc Med. (2017) 4:24. doi: 10.3389/fcvm.2017.00024

18. Demopoulos VP, Olympios CD, Fakiolas CN, Pissimissis EG, Economides NM, Adamopoulou E, et al. The natural history of aneurysmal coronary artery disease. Heart. (1997) 78:136-41. doi: 10.1136/hrt.78.2.136 
19. Giannoglou GD, Antoniadis AP, Chatzizisis YS, Damvopoulou E, Parcharidis GE, Louridas GE. Prevalence of ectasia in human coronary arteries in patients in northern Greece referred for coronary angiography. Am J Cardiol. (2006) 98:314-8. doi: 10.1016/j.amjcard.2006.02.034

20. Qin Y, Tang C, Ma C, Yan G. Risk factors for coronary artery ectasia and the relationship between hyperlipidemia and coronary artery ectasia. Coron Artery Dis. (2019) 30:211-5. doi: 10.1097/MCA.0000000000000709

21. Sudhir K, Ports TA, Amidon TM, Goldberger JJ, Bhushan V, Kane $\mathrm{JP}$, et al. Increased prevalence of coronary ectasia in heterozygous familial hypercholesterolemia. Circulation. (1995) 91:1375-80. doi: 10.1161/01.CIR.91.5.1375

22. Bahremand M, Zereshki E, Matin BK, Rezaei M, Omrani H. Hypertension and coronary artery ectasia: a systematic review and meta-analysis study. Clin Hypertens. (2021) 27:14. doi: 10.1186/s40885-021-00170-6

23. Satran A, Bart BA, Henry CR, Murad MB, Talukdar S, Satran D, et al. Increased prevalence of coronary artery aneurysms among cocaine users. Circulation. (2005) 111:2424-9. doi: 10.1161/01.CIR.0000165121.50527.DE

24. Androulakis AE, Andrikopoulos GK, Kartalis AN, Stougiannos PN, Katsaros AA, Syrogiannidis DN, et al. Relation of coronary artery ectasia to diabetes mellitus. Am J Cardiol. (2004) 93:1165-7. doi: 10.1016/j.amjcard.2004.01.049

25. Pinar Bermúdez E, López Palop R, Lozano Martínez-Luengas I, Cortés Sánchez R, Carrillo Sáez P, Rodríguez Carreras R, et al. [Coronary ectasia: prevalence, and clinical and angiographic characteristics]. Rev Esp Cardiol. (2003) 56:473-9. doi: 10.1016/S0300-8932(03)76902-4

26. Zografos TA, Korovesis S, Giazitzoglou E, Kokladi M, Venetsanakos I, Paxinos G, et al. Clinical and angiographic characteristics of patients with coronary artery ectasia. Int J Cardiol. (2013) 167:1536-41. doi: 10.1016/j.ijcard.2012.04.098

27. Balderston JR, Giri J, Kolansky DM, Bavaria JE, Gertz ZM. Coronary artery aneurysms associated with ascending aortic aneurysms and abdominal aortic aneurysms: pathophysiologic implications. Catheter Cardiovasc Interv. (2015) 85:961-7. doi: $10.1002 / \mathrm{ccd} .25726$

28. Meindl C, Achatz B, Huber D, Baessler A, Hubauer U, Meisinger $\mathrm{C}$, et al. Coronary artery ectasia are frequently observed in patients with bicuspid aortic valves with and without dilatation of the ascending aorta. Circ Cardiovasc Interv. (2016) 9:e004092. doi: 10.1161/CIRCINTERVENTIONS.116.004092

29. Roberts WC. Natural history, clinical consequences, and morphologic features of coronary arterial aneurysms in adults. Am J Cardiol. (2011) 108:814-21. doi: 10.1016/j.amjcard.2011.05.009

30. Daoud AS, Pankin D, Tulgan H, Florentin RA. Aneurysms of the coronary artery. Report of ten cases and review of literature. Am J Cardiol. (1963) 11:228-37. doi: 10.1016/0002-9149(63)90064-X

31. Yetkin E, Waltenberger J. Novel insights into an old controversy: is coronary artery ectasia a variant of coronary atherosclerosis? Clin Res Cardiol. (2007) 96:331-9. doi: 10.1007/s00392-007-0521-0

32. Befeler B, Aranda MJ, Embi A, Mullin FL, El-Sherif N, Lazzara R. Coronary artery aneurysms: study of the etiology, clinical course and effect on left ventricular function and prognosis. Am J Med. (1977) 62:597-607. doi: 10.1016/0002-9343(77)90423-5

33. Virmani R, Robinowitz M, Atkinson JB, Forman MB, Silver MD, McAllister HA. Acquired coronary arterial aneurysms: an autopsy study of 52 patients. Hum Pathol. (1986) 17:575-83. doi: 10.1016/S0046-8177(86) 80129-0

34. Lamblin N, Bauters C, Hermant X, Lablanche JM, Helbecque N, Amouyel P. Polymorphisms in the promoter regions of MMP-2, MMP-3, MMP-9 and MMP-12 genes as determinants of aneurysmal coronary artery disease. J Am Coll Cardiol. (2002) 40:43-8. doi: 10.1016/S0735-1097(02)01909-5

35. Finkelstein A, Michowitz Y, Abashidze A, Miller H, Keren G, George J. Temporal association between circulating proteolytic, inflammatory and neurohormonal markers in patients with coronary ectasia. Atherosclerosis. (2005) 179:353-9. doi: 10.1016/j.atherosclerosis.2004.10.020

36. Turhan H, Erbay AR, Yasar AS, Aksoy Y, Bicer A, Yetkin G, et al. Plasma soluble adhesion molecules; intercellular adhesion molecule-1, vascular cell adhesion molecule-1 and E-selectin levels in patients with isolated coronary artery ectasia. Coron Artery Dis. (2005) 16:45-50. doi: 10.1097/00019501-200502000-00009
37. Dereli S, Çerik I B, Kaya A, Bektaş O. Assessment of the relationship between c-reactive protein-to-albumin ratio and the presence and severity of isolated coronary artery ectasia. Angiology. (2020) 71:840-6. doi: 10.1177/0003319720930983

38. Franco-Peláez JA, Martín-Reyes R, Pello-Lázaro AM, Aceña Á, Lorenzo Ó, Martín-Ventura JL, et al. Monocyte chemoattractant protein-1 is an independent predictor of coronary artery ectasia in patients with acute coronary syndrome. J Clin Med. (2020) 9:3037. doi: 10.3390/jcm9093037

39. Boles U, Johansson A, Wiklund U, Sharif Z, David S, McGrory $\mathrm{S}$, et al. Cytokine disturbances in coronary artery ectasia do not support atherosclerosis pathogenesis. Int J Mol Sci. (2018) 19:260. doi: 10.3390/ijms19010260

40. Haroun RR, Chu LC, Fishman EK. Prevalence and natural history of coronary ostial aneurysms in marfan patients. J Comput Assist Tomogr. (2019) 43:115-8. doi: 10.1097/RCT.0000000000000799

41. Restrepo CS, Gonzalez TV, Baxi A, Rojas CA. Infected ("Mycotic") coronary artery aneurysm: systematic review. J Cardiovasc Comput Tomogr. (2020) 14:e99-104. doi: 10.1016/j.jcct.2019.01.018

42. Newburger JW, Takahashi M, Burns JC. Kawasaki disease. J Am Coll Cardiol. (2016) 67:1738-49. doi: 10.1016/j.jacc.2015.12.073

43. Newburger JW, Takahashi M, Gerber MA, Gewitz MH, Tani LY, Burns JC, et al. Diagnosis, treatment, and long-term management of Kawasaki disease: a statement for health professionals from the Committee on Rheumatic Fever, Endocarditis and Kawasaki Disease, Council on Cardiovascular Disease in the Young, American Heart Association. Circulation. (2004) 110:2747-71. doi: 10.1161/01.CIR.0000145143.19711.78

44. Kuo HC, Li SC, Huang LH, Huang YH. Epigenetic hypomethylation and upregulation of matrix metalloproteinase 9 in Kawasaki disease. Oncotarget. (2017) 8:60875-91. doi: 10.18632/oncotarget.19650

45. Senzaki H. The pathophysiology of coronary artery aneurysms in Kawasaki disease: role of matrix metalloproteinases. Arch Dis Childh. (2006) 91:84751. doi: 10.1136/adc.2005.087437

46. Aoki J, Kirtane A, Leon MB, Dangas G. Coronary artery aneurysms after drug-eluting stent implantation. JACC Cardiovasc Interv. (2008) 1:14-21. doi: 10.1016/j.jcin.2007.10.004

47. Condado JA, Waksman R, Gurdiel O, Espinosa R, Gonzalez J, Burger $\mathrm{B}$, et al. Long-term angiographic and clinical outcome after percutaneous transluminal coronary angioplasty and intracoronary radiation therapy in humans. Circulation. (1997) 96:727-32. doi: 10.1161/01.CIR.96.3.727

48. Hayashi T, Tanaka Y, Shishido K, Yokota S, Moriyama N, Tobita K, et al. wire bias, insufficient differential sanding, and orbital atherectomy-induced coronary pseudoaneurysm. Circ Cardiovasc Interv. (2018) 11:e007003. doi: 10.1161/CIRCINTERVENTIONS.118.007003

49. Bell MR, Garratt KN, Bresnahan JF, Edwards WD, Holmes DR, Jr. Relation of deep arterial resection and coronary artery aneurysms after directional coronary atherectomy. J Am Coll Cardiol. (1992) 20:1474-81. doi: 10.1016/0735-1097(92)90439-T

50. Joner M, Finn AV, Farb A, Mont EK, Kolodgie FD, Ladich E, et al. Pathology of drug-eluting stents in humans: delayed healing and late thrombotic risk. $J$ Am Coll Cardiol. (2006) 48:193-202. doi: 10.1016/j.jacc.2006.03.042

51. Bavry AA, Chiu JH, Jefferson BK, Karha J, Bhatt DL, Ellis SG, et al. Development of coronary aneurysm after drugeluting stent implantation. Ann Intern Med. (2007) 146:230-2. doi: 10.7326/0003-4819-146-3-200702060-00146

52. Torii S, Jinnouchi H, Sakamoto A, Kutyna M, Cornelissen A, Kuntz S, et al. Drug-eluting coronary stents: insights from preclinical and pathology studies. Nat Rev Cardiol. (2020) 17:37-51. doi: 10.1038/s41569-019-0234-x

53. La Manna A, Mangiameli A, Capodanno D, Longo G, Sgroi C, Tamburino C. Managing bioabsorbable vascular scaffold failure: combined scaffold restenosis and late-acquired coronary aneurysm treated with selfexpandable stent. Can J Cardiol. (2015) 31:691.e1-3. doi: 10.1016/j.cjca.2014. 12.021

54. Gargiulo G, Mangiameli A, Granata F, Ohno Y, Chisari A, Capodanno $D$, et al. New-onset coronary aneurism and late-acquired incomplete scaffold apposition after full polymer jacket of a chronic total occlusion with bioresorbable scaffolds. JACC Cardiovasc Interv. (2015) 8:e41-3. doi: $10.1016 /$ j.jcin.2014.10.022 
55. Varghese S, Lauer B, Ohlow MA. Coronary Artery aneurysm after everolimus-eluting bioabsorbable vascular scaffold implantation. JACC Cardiovasc Interv. (2016) 9:e23-5. doi: 10.1016/j.jcin.2015.10.032

56. Ramirez FD, Hibbert B, Simard T, Pourdjabbar A, Wilson KR, Hibbert R, et al. Natural history and management of aortocoronary saphenous vein graft aneurysms: a systematic review of published cases. Circulation. (2012) 126:2248-56. doi: 10.1161/CIRCULATIONAHA.112.101592

57. Vinciguerra M, Spadaccio C, Tennyson C, Karuppannan M, Bose A, Greco E, et al. Management of patients with aortocoronary saphenous vein graft aneurysms: jacc state-of-the-art review. J Am Coll Cardiol. (2021) 77:2236-53. doi: 10.1016/j.jacc.2021.03.009

58. Rath S, Har-Zahav Y, Battler A, Agranat O, Rotstein Z, Rabinowitz $\mathrm{B}$, et al. Fate of nonobstructive aneurysmatic coronary artery disease: angiographic and clinical follow-up report. Am Heart J. (1985) 109:785-91. doi: 10.1016/0002-8703(85)90639-8

59. Chrissoheris MP, Donohue TJ, Young RS, Ghantous A. Coronary artery aneurysms. Cardiol Rev. (2008) 16:116-23. doi: 10.1097/CRD.0b013e31815d0573

60. Ebina T, Ishikawa Y, Uchida K, Suzuki S, Imoto K, Okuda J, et al. A case of giant coronary artery aneurysm and literature review. J Cardiol. (2009) 53:293-300. doi: 10.1016/j.jjcc.2008.07.015

61. Ge J, Liu F, Kearney P, Görge G, Haude M, Baumgart D, et al. Intravascular ultrasound approach to the diagnosis of coronary artery aneurysms. Am Heart J. (1995) 130:765-71. doi: 10.1016/0002-8703(95)90075-6

62. Ali ZA, Karimi Galougahi K, Mintz GS, Maehara A, Shlofmitz RA, Mattesini A. Intracoronary optical coherence tomography: state of the art and future directions. Eurointervention. (2021) 17:e105-23. doi: 10.4244/EIJ-D-21-00089

63. Díaz-Zamudio M, Bacilio-Pérez U, Herrera-Zarza MC, Meave-González A, Alexanderson-Rosas E, Zambrana-Balta GF, et al. Coronary artery aneurysms and ectasia: role of coronary CT angiography. Radiographics. (2009) 29:1939-54. doi: 10.1148/rg.297095048

64. Forte $\mathrm{E}$, Aiello $\mathrm{M}$, Inglese $\mathrm{M}$, Infante $\mathrm{T}$, Soricelli $\mathrm{A}$, Tedeschi C, et al. Coronary artery aneurysms detected by computed tomography coronary angiography. Eur Heart J Cardiovasc Imaging. (2017) 18:1229-35. doi: 10.1093/ehjci/jew218

65. Touma R, Palla M, Alam K, Mastromatteo JF, Abidov A. Giant calcified left circumflex coronary artery aneurysm with complex coronaryto-left ventricular communication. JACC Case Rep. (2020) 2:1812-7. doi: 10.1016/j.jaccas.2020.04.059

66. Gupta A, Datta R, Chhikara S, Dhagat PK, Vijayvergiya R. Coronary artery aneurysm after drug-eluting stent implantation causing coronary-bronchial fistula. JACC Case Rep. (2020) 2:1692-7. doi: 10.1016/j.jaccas.2020.07.041

67. Mavrogeni SI, Manginas A, Papadakis E, Foussas S, Douskou M, Baras $\mathrm{P}$, et al. Correlation between magnetic resonance angiography (MRA) and quantitative coronary angiography (QCA) in ectatic coronary vessels. $J$ Cardiovasc Magn Reson. (2004) 6:17-23. doi: 10.1081/JCMR-120027801

68. Greil GF, Stuber M, Botnar RM, Kissinger KV, Geva T, Newburger JW, et al. Coronary magnetic resonance angiography in adolescents and young adults with Kawasaki disease. Circulation. (2002) 105:908-11. doi: 10.1161/hc0802.105563

69. Baman TS, Cole JH, Devireddy CM, Sperling LS. Risk factors and outcomes in patients with coronary artery aneurysms. Am J Cardiol. (2004) 93:1549-51. doi: 10.1016/j.amjcard.2004.03.011

70. Bogana Shanmugam V, Psaltis PJ, Wong DTL, Meredith IT, Malaiapan Y, Ahmar W. outcomes after primary percutaneous coronary intervention for st-elevation myocardial infarction caused by ectatic infarct related arteries. Heart Lung Circ. (2017) 26:1059-68. doi: 10.1016/j.hlc.2016.12.006

71. Mir T, Sattar Y, Uddin M, Changal KH, Kumar K, Attique HB, et al. Post-PCI outcomes in STEMI patients with coronary ectasia: meta-analysis. Expert Rev Cardiovasc Ther. (2021) 19:349-56. doi: 10.1080/14779072.2021.1889370

72. Ipek G, Gungor B, Karatas MB, Onuk T, Keskin M, Tanik O, et al. Risk factors and outcomes in patients with ectatic infarct-related artery who underwent primary percutaneous coronary intervention after ST elevated myocardial infarction. Catheter Cardiovasc Interv. (2016) 88:74853. doi: $10.1002 / \mathrm{ccd} .26553$

73. Erden I, Erden EC, Ozhan H, Karabulut A, Ordu S, Yazici M. Outcome of primary percutaneous intervention in patients with infarct-related coronary artery ectasia. Angiology. (2010) 61:574-9. doi: 10.1177/00033197093 61197

74. Wang X, Montero-Cabezas JM, Mandurino-Mirizzi A, Hirasawa K, Ajmone Marsan N, Knuuti J, et al. Prevalence and long-term outcomes of patients with coronary artery ectasia presenting with acute myocardial infarction. Am J Cardiol. (2021) 156:9-15. doi: 10.1016/j.amjcard.2021.06.037

75. Cai Z, Liu J, Wang H, Yin D, Song W, Dou K. Diffuse coronary artery dilation predicted worse long-term outcomes in patients with coronary artery Ectasia. Int J Cardiol. (2020) 319:20-5. doi: 10.1016/j.ijcard.2020.05.054

76. Will M, Kwok CS, Nagaraja V, Potluri R, Weiss TW, Mascherbauer $\mathrm{J}$, et al. Outcomes of patients who undergo elective covered stent treatment for coronary artery aneurysms. Cardiovasc Revasc Med. (2021). doi: 10.1016/j.carrev.2021.05.018. [Epub ahead of print].

77. Khubber S, Chana R, Meenakshisundaram C, Dhaliwal K, Gad M, Kaur M, et al. Coronary artery aneurysms: outcomes following medical, percutaneous interventional and surgical management. Open Heart. (2021) 8:e001440. doi: 10.1136/openhrt-2020-001440

78. D’Ascenzo F, Saglietto A, Ramakrishna H, Andreis A, Jiménez-Mazuecos JM, Nombela-Franco L, et al. Usefulness of oral anticoagulation in patients with coronary aneurysms: insights from the CAAR registry. Catheter Cardiovasc Interv. (2020) 98:864-71. doi: 10.1002/ccd.29243

79. Schram HCF, Hemradj VV, Hermanides RS, Kedhi E, Ottervanger JP. Coronary artery ectasia, an independent predictor of no-reflow after primary PCI for ST-elevation myocardial infarction. Int J Cardiol. (2018) 265:12-7. doi: 10.1016/j.ijcard.2018.04.120

80. Iannopollo G, Ferlini M, Koziński M, Ormezzano MF, Crimi G, Lanfranchi $\mathrm{L}$, et al. Patient outcomes with STEMI caused by aneurysmal coronary artery disease and treated with primary PCI. J Am Coll Cardiol. (2017) 69:3006-7. doi: 10.1016/j.jacc.2017.04.030

81. Núñez-Gil IJ, Terol B, Feltes G, Nombela-Franco L, Salinas P, Escaned J, et al. Coronary aneurysms in the acute patient: Incidence, characterization and long-term management results. Cardiovasc Revasc Med. (2018) 19:589-96. doi: 10.1016/j.carrev.2017.12.003

82. Campanile A, Sozzi FB, Consonni D, Piscione F, Sganzerla P, Indolfi C, et al. Primary PCI for the treatment of ectatic infarct-related coronary artery. Minerva Cardioangiol. (2014) 62:327-33.

83. Boyer N, Gupta R, Schevchuck A, Hindnavis V, Maliske S, Sheldon M, et al. Coronary artery aneurysms in acute coronary syndrome: case series, review, and proposed management strategy. J Invas Cardiol. (2014) 26:283-90.

84. Carrick D, Oldroyd KG, McEntegart M, Haig C, Petrie MC, Eteiba $\mathrm{H}$, et al. A randomized trial of deferred stenting versus immediate stenting to prevent no- or slow-reflow in acute ST-segment elevation myocardial infarction (DEFER-STEMI). J Am Coll Cardiol. (2014) 63:208898. doi: 10.1016/j.jacc.2014.02.530

85. Lønborg J, Engstrøm T, Ahtarovski KA, Nepper-Christensen L, Helqvist S, Vejlstrup N, et al. Myocardial damage in patients with deferred stenting after STEMI: A DANAMI-3-DEFER substudy. J Am Coll Cardiol. (2017) 69:2794-804. doi: 10.1016/j.jacc.2017.03.601

86. Dangas GD, Claessen BE, Mehran R, Xu K, Fahy M, Parise H, et al. Development and validation of a stent thrombosis risk score in patients with acute coronary syndromes. JACC Cardiovascular interventions. (2012) 5:1097-105. doi: 10.1016/j.jcin.2012.07.012

87. Tehrani S, Faircloth M, Chua TP, Rathore S. Percutaneous coronary intervention in coronary artery aneurysms; technical aspects. Report of case series and literature review. Cardiovasc Revasc Med. (2021) 28s:243-8. doi: 10.1016/j.carrev.2020.12.010

88. Kaneko U, Kashima Y, Hashimoto M, Fujita T. Very late stent migration within a giant coronary aneurysm in a patient with Kawasaki disease: assessment with multidetector computed tomography. JACC Cardiovasc Interv. (2017) 10:1799-800. doi: 10.1016/j.jcin.2017.05.016

89. Cereda AF, Tiberti G, Pera IG, Cantù E, Ferri LA, Savonitto S, et al. A giant coronary artery aneurysm treated using multiple overlapping covered stents. JACC Cardiovasc Interv. (2017) 10:e127-8. doi: 10.1016/j.jcin.2017.04.030

90. Witzenbichler B, Maehara A, Weisz G, Neumann FJ, Rinaldi MJ, Metzger DC, et al. Relationship between intravascular ultrasound guidance and clinical outcomes after drug-eluting stents: the assessment of dual antiplatelet therapy with drug-eluting stents (ADAPT-DES) study. Circulation. (2014) 129:463-70. doi: 10.1161/CIRCULATIONAHA.113.003942 
91. Warisawa T, Suzuki N, Kasahara M, Okuyama K, Matsuda H, Akashi YJ. Successful exclusion of coronary artery aneurysm by utilizing shortening of covered stent to avoid side-branch occlusion. Cardiovasc Interv Ther. (2021). doi: 10.1007/s12928-020-00740-9. [Epub ahead of print].

92. Seth A, Singh VP. Polytetrafluoroethylene covered stents during PCI: wanting more from our "savior". Catheter Cardiovasc Interv. (2019) 94:5623. doi: $10.1002 / \mathrm{ccd} .28517$

93. Davies RE, Cheney AE, McCabe JM, Alaswad K, Lombardi WL. A novel hybrid approach to the treatment of a left main coronary artery aneurysm. JACC Case Rep. (2020) 2:1675-8. doi: 10.1016/j.jaccas.2020.07.036

94. Adusumalli S, Gaikwad N, Raffel C, Dautov R. Treatment of rotablationinduced ostial left circumflex perforation by papyrus covered stent and its fenestration to recover the left anterior descending artery during CHIP procedure. Catheter Cardiovasc Interv. (2019) 93:E331-6. doi: $10.1002 / \mathrm{ccd} .28114$

95. Nagaraja V, Schwarz K, Moss S, Kwok CS, Gunning M. Outcomes of patients who undergo percutaneous coronary intervention with covered stents for coronary perforation: a systematic review and pooled analysis of data. Catheter Cardiovasc Interv. (2020) 96:1360-6. doi: 10.1002/ccd.28646

96. Hernández-Enríquez M, Belle L, Madiot H, Pansieri M, Souteyrand G, de Poli F, et al. Use and outcomes of the PK Papyrus covered stent in France: SOS PK Papyrus Registry. Catheter Cardiovasc Interv. (2020) 98:874-81. doi: $10.1002 / \mathrm{ccd} .29328$

97. Al-Lamee R, Ielasi A, Latib A, Godino C, Ferraro M, Mussardo M, et al. Incidence, predictors, management, immediate and long-term outcomes following grade III coronary perforation. JACC Cardiovasc Interv. (2011) 4:87-95. doi: 10.1016/j.jcin.2010.08.026

98. El-Hayek G, Bangalore S, Casso Dominguez A, Devireddy C, Jaber W, Kumar G, et al. Meta-analysis of randomized clinical trials comparing biodegradable polymer drug-eluting stent to second-generation durable polymer drug-eluting stents. JACC Cardiovasc Interv. (2017) 10:462-73. doi: 10.1016/j.jcin.2016.12.002

99. Stankovic G, Colombo A, Presbitero P, van den Branden F, Inglese L, Cernigliaro $\mathrm{C}$, et al. Randomized evaluation of polytetrafluoroethylene-covered stent in saphenous vein grafts: the Randomized Evaluation of polytetrafluoroethylene COVERed stent in Saphenous vein grafts (RECOVERS) Trial. Circulation. (2003) 108:37-42. doi: 10.1161/01.CIR.0000079106.71097.1C

100. Ravi S, Chaikof EL. Biomaterials for vascular tissue engineering. Regenerat Med. (2010) 5:107-20. doi: 10.2217/rme.09.77

101. Bossard M, Cioffi GM, Yildirim M, Moccetti F, Wolfrum M, Attinger A, et al. "Burying" covered coronary stents under drug-eluting stents: a novel approach to ensure long-term stent patency. Cardiol J. (2021). doi: 10.5603/CJ.a2021.0096. [Epub ahead of print].

102. Win HK, Polsani V, Chang SM, Kleiman NS. Stent-assisted coil embolization of a large fusiform aneurysm of proximal anterior descending artery: novel treatment for coronary aneurysms. Circ Cardiovasc Interv. (2012) 5:e3-5. doi: 10.1161/CIRCINTERVENTIONS.111.966754

103. Saccà S, Pacchioni A, Nikas D. Coil embolization for distal left main aneurysm: a new approach to coronary artery aneurysm treatment. Catheter Cardiovasc Interv. (2012) 79:1000-3. doi: 10.1002/ccd.23195

104. Citro R, Iuliano G, Baldi C, Iesu S. A time bomb defused, in time! Incidental giant right coronary artery aneurysm. Eur Heart J. (2019) 40:2619. doi: 10.1093/eurheartj/ehz341

105. Harandi S, Johnston SB, Wood RE, Roberts WC. Operative therapy of coronary arterial aneurysm. Am J Cardiol. (1999) 83:1290-3. doi: 10.1016/S0002-9149(99)00079-X

106. Singh SK, Goyal T, Sethi R, Chandra S, Devenraj V, Rajput NK, et al. Surgical treatment for coronary artery aneurysm: a single-centre experience. Interact Cardiovasc Thorac Surg. (2013) 17:632-6. doi: 10.1093/icvts/ivt282

107. Sengupta D, Kahn AM, Kung E, Esmaily Moghadam M, Shirinsky O, Lyskina GA, et al. Thrombotic risk stratification using computational modeling in patients with coronary artery aneurysms following Kawasaki disease. Biomech Model Mechanobiol. (2014) 13:1261-76. doi: 10.1007/s10237-014-0570-z

108. Yasar AS, Erbay AR, Ayaz S, Turhan H, Metin F, Ilkay E, et al. Increased platelet activity in patients with isolated coronary artery ectasia. Coron Artery Dis. (2007) 18:451-4. doi: 10.1097/MCA.0b013e3282a 30665
109. Warisawa T, Naganuma T, Tomizawa N, Fujino Y, Ishiguro H, Tahara S, et al. High prevalence of coronary artery events and non-coronary events in patients with coronary artery aneurysm in the observational group. Int $J$ Cardiol Heart Vasc. (2016) 10:29-31. doi: 10.1016/j.ijcha.2015.10.005

110. Antonopoulos AS, Siasos G, Oikonomou E, Mourouzis K, Mavroudeas SE, Papageorgiou N, et al. Characterization of vascular phenotype in patients with coronary artery ectasia: the role of endothelial dysfunction. Int J Cardiol. (2016) 215:138-9. doi: 10.1016/j.ijcard.2016.04.046

111. Fan $\mathrm{CH}$, Hao Y, Liu $\mathrm{YH}$, Li XL, Huang $\mathrm{ZH}$, Luo $\mathrm{Y}$, et al. Antiinflammatory effects of rosuvastatin treatment on coronary artery ectasia patients of different age groups. BMC Cardiovasc Disord. (2020) 20:330. doi: 10.1186/s12872-020-01604-Z

112. Gülec S, Aras O, Atmaca Y, Akyürek O, Hanson NQ, Sayin T, et al. Deletion polymorphism of the angiotensin I converting enzyme gene is a potent risk factor for coronary artery ectasia. Heart. (2003) 89:213-4. doi: 10.1136/heart.89.2.213

113. Jackson G, Atkinson L, Oram S. Improvement of myocardial metabolism in coronary arterial disease by beta-blockade. Br Heart J. (1977) 39:829-33. doi: 10.1136/hrt.39.8.829

114. Sorrell VL, Davis MJ, Bove AA. Current knowledge and significance of coronary artery ectasia: a chronologic review of the literature, recommendations for treatment, possible etiologies, and future considerations. Clin Cardiol. (1998) 21:157-60. doi: 10.1002/clc.4960210304

115. Ozcan OU, Atmaca Y, Goksuluk H, Akbulut IM, Ozyuncu N, Ersoy N, et al. Effect of diltiazem on coronary artery flow and myocardial perfusion in patients with isolated coronary artery ectasia and either stable angina pectoris or positive myocardial ischemic stress test. Am J Cardiol. (2015) 116:1199-203. doi: 10.1016/j.amjcard.2015.07.033

116. Dogan A, Ozaydin M, Gedikli O, Altinbas A, Ergene O. Effect of trimetazidine on exercise performance in patients with coronary artery ectasia. Jpn Heart J. (2003) 44:463-70. doi: 10.1536/jhj.44.463

117. Al-Makhamreh HK, Shaban AE, AlHaddadin SS, AlSharif AA, Ghalayni RA, Daoud LF, et al. Is lipoprotein (a) a risk factor for coronary artery ectasia? Cardiol Res. (2020) 11:50-5. doi: 10.14740/cr992

118. Kubota Y, Folsom AR, Ballantyne CM, Tang W. Lipoprotein(a) and abdominal aortic aneurysm risk: the Atherosclerosis Risk in Communities study. Atherosclerosis. (2018) 268:63-7. doi: 10.1016/j.atherosclerosis.2017.10.017

119. Phillips J, Roberts G, Bolger C, el Baghdady A, Bouchier-Hayes D, Farrell $\mathrm{M}$, et al. Lipoprotein (a): a potential biological marker for unruptured intracranial aneurysms. Neurosurgery. (1997) 40:1112-5; discussion 5-7. doi: 10.1097/00006123-199705000-00067

120. Galasso G, De Angelis E, Silverio A, Di Maio M, Cancro FP, Esposito L, et al. Predictors of recurrent ischemic events in patients with STsegment elevation myocardial infarction. Am J Cardiol. (2021) 159:44-51. doi: 10.1016/j.amjcard.2021.08.019

121. Gencer B, Kronenberg F, Stroes ES, Mach F. Lipoprotein(a): the revenant. Eur Heart J. (2017) 38:1553-60. doi: 10.1093/eurheartj/ehx033

122. Nordestgaard BG, Chapman MJ, Ray K, Borén J, Andreotti F, Watts GF, et al. Lipoprotein(a) as a cardiovascular risk factor: current status. Eur Heart J. (2010) 31:2844-53. doi: 10.1093/eurheartj/ehq386

Conflict of Interest: The authors declare that the research was conducted in the absence of any commercial or financial relationships that could be construed as a potential conflict of interest.

Publisher's Note: All claims expressed in this article are solely those of the authors and do not necessarily represent those of their affiliated organizations, or those of the publisher, the editors and the reviewers. Any product that may be evaluated in this article, or claim that may be made by its manufacturer, is not guaranteed or endorsed by the publisher.

Copyright (C) 2022 Esposito, Di Maio, Silverio, Cancro, Bellino, Attisano, Tarantino, Esposito, Vecchione, Galasso and Baldi. This is an open-access article distributed under the terms of the Creative Commons Attribution License (CC BY). The use, distribution or reproduction in other forums is permitted, provided the original author(s) and the copyright owner(s) are credited and that the original publication in this journal is cited, in accordance with accepted academic practice. No use, distribution or reproduction is permitted which does not comply with these terms. 